\title{
Öğretmen Adaylarının Öğretmenlik Mesleğini Seçme Nedenleri, Beklentileri ve Öğretmenlik Programının Niteliğinin Artırılmasına Yönelik Görüşleri
}

\author{
Mehmet Yaşar KILIÇ*
}

- Geliş Tarihi: 02.12.2021 • Kabul Tarihi: 21.02.2022 •Çevrimiçi Yayın Tarihi: 21.02.2022

\section{$\ddot{\mathbf{O} z}$}

Bu çalışmanın amacı, öğretmen adaylarının öğretmenlik mesleğini seçme nedenlerinin, öğretmenlik mesleğinden beklentilerinin ve öğretmenlik programının niteliğinin artırılmasına yönelik görüşlerinin belirlenmesidir. Araştırma nitel analiz yöntemlerinden durum çalışmasına uygun olarak yürütülmüştür. Araştırmanın katılımcılarını 2020-2021 eğitim öğretim yılında eğitim fakültesinde eğitim gören 23 öğretmen adayı oluşturmaktadır. Katılımcılar amaçlı örnekleme yöntemlerinden kolay ulaşılabilir örnekleme yöntemi ile belirlenmiştir. Çalışmada veri toplama aracı olarak, araştırmacı tarafından oluşturulan yarı yapılandırılmış görüşme formu kullanılmıştır. Toplanan verilere NVivo 10 nitel analiz programı ile "içerik analizi” yapılmıştır. İçerik analizi sonucunda her bir araştırma sorusu için ayrı tablo oluşturulmuştur. Araştırma sonucunda göre öğretmen adaylarının öğretmenlik mesleğini seçme nedenleri dışsal sebepler, özgeci sebepler ve içsel sebepler olarak üç alt tema altında toplandığı görülmüştür. Bunun yanı sıra öğretmen adaylarının öğretmenlik mesleğinden beklentilerinin mesleki beklentiler, sosyal beklentiler ve ekonomik beklentiler olarak üç alt tema altında toplandığı sonucuna ulaşılmıştır. Öğretmen adaylarının öğretmenlik programının niteliğinin artırılmasına yönelik görüşleri değerlendirildiğinde ise daha fazla uygulamalı ders olmalı, giriş şartları düzenlenmeli, öğrenci sayısı azaltılmalı, tecrübeli öğretim elemanı, etkili iletişim, yeterli destek, fiziki imkânlar kategorileri elde edilmiştir. Ayrıca öğretmen adaylarının ikinci bir tercih yapma şansları olması durumunda büyük bir çoğunluğu, yeniden öğretmenlik mesleğini seçeceklerini belirtmiştir. Bunun yanı sıra bazı öğretmen adayları farklı meslekleri seçebileceğini ifade etmektedir.

Anahtar sözcükler: öğretmen adayları, öğretmen beklentileri, öğretmen nitelikleri, öğretmenlik mesleği, öğretmenlik programı

Atıf:

Kılıç, M.Y. (2022). Öğretmen adaylarının öğretmenlik mesleğini seçme nedenleri, beklentileri ve öğretmenlik programının niteliğinin artırılmasına yönelik görüşleri. Pamukkale Üniversitesi Eğitim Fakültesi Dergisi, 56, 35-65, doi:10.9779.pauefd.1031456

\footnotetext{
* Dr. Öğr. Üyesi, Kıbrıs İlim Üniversitesi, ORCID: 0000-0002-8675-5126, myasarkilic@ @su.edu.tr
} 


\section{Giriş}

Günümüzde teknolojik, ekonomik, sosyal ve kültürel alanlarda yaşanan değişimler ve gelişimler birçok sistemi etkilediği gibi eğitim sistemini de etkilemekte ve bunun sonucunda birçok değişimi beraberinde getirmektedir. Eğitim sisteminin ülkelerin kalkınması için gerekli düzeyde bilgi ve becerilere sahip bireylerin yetiştirilmesinde, teknolojik, ekonomik, sosyal ve kültürel devamlılıklarının sağlanmasında önemli işlevi bulunmaktadır. Eğitim sisteminin niteliği sistemin gerekliliklerini etkin bir şekilde yerine getirebilecek nitelikli öğretmenlere bağlıdır (Karadağ, 2012). Öğretmenlik, bireylerin ve toplumun yaşam biçimini şekillendiren ve toplumların geleceğine yön veren stratejik bir meslektir (Alkan, 2000). Eğitim sisteminin temel taşları olan öğretmenlerin verimlilikleri, eğitim-öğretim kalitesini direkt olarak etkilemektedir (Ergün ve Avc1, 2012). Dolayısıyla gelecek nesilleri yetiştirecek olan öğretmen adaylarının da nitelikli bir şekilde yetiştirilmesi gerekmektedir. Bu nedenle bu çalışmada öğretmen adaylarının öğretmenlik mesleğini seçme nedenleri, beklentileri ve öğretmenlik programının niteliğinin artırılmasına yönelik görüşlerinin belirlenmesi üzerinde çalışılmıştır.

\section{Meslek Seçimi ve Meslek Seçimini Etkileyen Faktörler}

Öğretmen adaylarının sahip olması gereken niteliklerin artırılabilmesi için öğretmen adaylarının mesleği tercih nedenleri ve meslekten beklentileri belirleyici rol oynamaktadır (Hacıömeroğlu ve Taşkın, 2010; Tataroğlu, Özgen ve Alkan, 2011). Nitelikli öğretmen olabilmek için bireyin mesleğini bilinçli olarak seçmesi, mesleğini sevmesi ve bireysel özellikleri ile öğretmenlik mesleğinin gerektirdiği özellikler arasında uyum olması gerekmektedir (Şara ve Kocabaş, 2012). Bireylerin kendi istek ve yeteneklerine uygun bir meslek seçmemesi durumunda, durumdan olumsuz etkilenmesi ve mesleki doyumsuzluk yaşamaları muhtemeldir (Kuzgun, 2008). Bu durum pek çok meslek dalında olduğu gibi öğretmenlik mesleği için geçerlidir.

Yapılan çalışmalar, bireyin öğretmenlik mesleğini seçmesinde içsel, dışsal ve özgecil güdülerinin ön plana çıktığını göstermektedir (Balyer ve Özcan 2014; Moran, Kilpatrick, Abbot, Dallat ve McClune, 2001; Thomson, Turner ve Nietfeld 2012). İçsel güdüler bireyin öğretme isteği, öğretimin kendi için anlamı, konu hakkındaki bilgisi ve uzmanlığıyla ilgili doğal yönlerdir. Dışsal güdüler bireyin statüsü, maaşı, tatilleri ve çalışma koşulları gibi yönleri içerir. Özgecil güdüler ise öğretmenliğin değerli bir meslek olarak algılanması, bireyin öğretmenlikte fark yaratma isteği ve çocukların gelişimine katkıda bulunma gibi istekleri içermektedir. Öğretmenlerin mesleği seçme nedeninin içsel ve özgecil güdüler olduğu ülkelerin gelişmiş ülkeler olduğu, dışsal güdülerin olduğu ülkeler ise gelişmekte olan ülkeler olduğu belirtilmektedir (Azman 2013; Low, Lim, Ch'ng ve Goh, 2011). Papanastasiou ve Papanastasiou (1997) ABD ve Kıbrıs’ta ilköğretim öğretmen adayları üzerinde bir çalışma yürütmüştür. Araştırma sonucunda ABD'de bulunan öğretmen adaylarının mesleği seçme nedenlerinin içsel, Kıbrıs'ta ise dışsal nedenlerin daha etkili olduğu sonucuna 
ulaşılmıştır. Boz ve Boz (2008) tarafından yapılan çalışmada, kimya ve matematik öğretmen adaylarının, öğretmenlik mesleğini seçme nedenlerinin en büyük belirleyicisi olarak dışsal faktörler olarak belirlemiştir. Bunu içsel ve özgecil güdüler takip etmektedir. Bunun yanı sıra yapılan araştırma sonuçları, bireyin öğretmenlik mesleğine yönelik sahip olduğu güdülerinin, bu üç kavramın karışımından oluşması gerektiği, böylece öğretmenlik mesleğinde kalıcı olabileceği söylenmektedir (Sinclair, 2008).

\section{Öğretmen Beklentileri ve Nitelikleri}

Öğretmen adayları öğretmenlik mesleğinin kendisine sağlayacak pek çok durumu değerlendirerek, belirli bir beklenti içinde mesleklerini seçmiş olabilirler. Yani hizmet öncesi dönemde öğretmenlik mesleği ile ilgili zihinlerinde kurguladıkları beklentiler vardır (Gömleksiz, Kan ve Biçer, 2010). Mesleğin seçilmesiyle birlikle mesleğe ilişkin beklentiler oluşur (Uras ve Kunt, 2006). Bireylerin mesleki olarak beklentilerinin karşılanmaması iş tatminin sağlanmamasına neden olur. Bunun sonucu olarak bireyler iş ortamlarına ve yöneticilerine ilişkin olumsuz tutum geliştirirler (Can ve Soyer, 2008). Bireylerin beklentilerinin karşılanması, onların moralleri, güdülenmeleri ve iş doyumları üzerinde olumlu etkileri bulunmaktadır. Güdülenmiş ve iş doyumuna ulaşmış bireylerin işte daha çaba gösterdiği ve başarılı olma olasılıklarının yüksek olduğu belirtilmektedir (Uras ve Kunt, 2006). Öğretmen adaylarının beklentilerinin karşılanabilmesi için öğretmenlik programının istenilen düzeyde niteliğinin artırılması gerektiği düşünülmektedir.

Öğretmen eğitimi aday öğretmenlerin sınıfta, okulda veya farklı ortamlarda görevlerini verimli bir şekilde yerine getirebilmesi için gereksinim duyulan bilgi, beceri, tutum ve davranışlarla donatılmak için tasarlanan politikalar, uygulamalar, programlar ve çok boyutlu öğretim süreçlerini içermektedir. Öğretmen eğitimi, o ülkede yetişen bireylerin geleceğe hazırlanması için verilen değeri yansıtmaktadır. Bu nedenle her ülkenin eğitim politikalarında farklı uygulamalar görülebilmektedir. $\mathrm{Bu}$ nedenle günümüzde öğretmen eğitiminin niteliğinin artırılması süreci tartışmalı bir konudur (Öner ve Yılmaz, 2019). Dünyanın en başarılı eğitim sistemlerinde sürekli olarak öğretmenlerin niteliğinin artırılması üzerine odaklanılmıştır. Özellikle eğitim politikalarında, eğitim öğretim standardının üst seviyeye çıkarılmasına ve öğretmenlerin niteliğinin artırılmasına yönelik uygulamalar sıklıkla görülmektedir (Jamil, 2014). Bunun yanı sıra öğretmen adaylarının nasıl seçildiği, programa kabul edilen öğretmen adaylarının sahip oldukları özellikler, hizmet öncesinde aldıkları eğitimler, ders veren öğretim üyelerinin nitelikleri ve öğretim-öğretim ortamları da öğretmenlerin niteliklerini doğrundan veya dolaylı olarak etkilemektedir (Tunca, Alkın-Şahin, Oğuz ve Bahar-Güner, 2015). Yapılan çalışmalar incelendiğinde, öğretmenlerin niteliğinin öğrenci başarıs1 üzerinde önemli etkilerinin olduğu söylenebilir. Hattie (2009) tarafından yapılan çalışmada öğretmenlerin niteliğinin öğrencilerin okul başarısı üzerinde önemli bir belirleyici olduğu sonucuna varılmıştır. Benzer bir şekilde Camelia ve Elisabeta (2013) öğretmenlerin hizmet öncesi dönemde aldıkları eğitimin öğrenci başarısını olumlu olarak etkilediğini belirtmektedir. 
$\mathrm{Bu}$ çalışma kapsamında ayrıca öğretmen adaylarının ikinci bir tercih tercih yapma şansları olması durumunda tercih edebilecekleri meslekler sorulmuştur. $\mathrm{Bu}$ soru onların hangi mesleği seçmek istediklerinden ziyade seçtikleri meslekten memnun olup olmama durumu hakkında bilgi edinmek amacıyla sorulmuştur. Dolayısıyla bu durum öğretmen adaylarının yaptıkları mesleği sevip sevmemesi ile ilgilidir. Yıldırım ve Öner (2016) yaptıkları çalışma sonucunda etkili ve başarılı öğretmen olabilmek için öğretmenlerin mesleğini sevmeleri gerektiğini sonucuna ulaşmışlardır. Dolayısyla öğretmenlerin mesleğini sevmesi, mesleğinde başarıya ulaşabilmesi adına önemli bir etkendir.

Öğretmen yetiştirme uygulamalarında ve öğretmenlik mesleği çalışma koşullarında sürekli olarak değişiklikler yaşanmaktadır. Bundan dolayı öğretmenlik yetiştirme programlarında eğitim gören öğretmen adaylarının mesleklerine yönelik tutumlarının belirlenmesi ve güncel araştırmaların yapılması önemlidir (Üstüner, 2006). Eğitim sisteminin devamlılı̆̆ını sağlamak için öğretmen yetiştiren eğitim fakültelerinde, öğretmen adaylarının niteliklerinin artırılabilmesi ve bu yönde harekete geçilebilmesi adına onların mesleği seçme nedenleri ve meslekten beklentilerinin belirlenmesi gerekli bir durumdur. Öğretmen adaylarının bu konudaki düşüncelerinin ve beklentilerinin derinlemesine incelenmesi, öğretmen adaylarının yeterliğini artırabilmek adına derslerine giren öğretim üyelerine ve politika yapıcılara faydalı bilgiler sağlayabilir. Şahin (2011), toplumun geleceğini sağlıklı temeller üzerinde kurmak ve şekillendirmek için öğretmenlerin her açından donanımlı olarak yetiştirilmesi gerektiğini ve bunu sağlamak için ise öğretmen adaylarının geleceğe yönelik umutlarının canlı tutmak gerektiğini belirtmektedir. $\mathrm{Bu}$ açından bakıldığında gelecek nesilleri yetiştirecek olan öğretmen adaylarının meslekten beklentilerinin belirlenmesi eğitim öğretimin geliştirilmesine yönelik atılabilecek adımlar için önemlidir. Ayrıca öğretmen adaylarının öğretmenlik programının niteliğinin artırılmasına yönelik görüşlerinin belirlenmesinin öğretmenlik yetiştirme sürecinin, güncel beklentiler doğrultusunda yapılandırılması adına önemli katkıları olabileceği düşünülmektedir. Elde edilecek sonuçların öğretmen yetiştirme sürecinin daha verimli ve etkili olarak gerçekleştirilmesine, öğretmenlik programlarının niteliğinin artırılmasına, bu doğrultuda program ile ilgili yapılacak planlamalar için kaynak oluşturabileceği umulmaktadır. Bunun yanı sıra elde edilecek sonuçların araştırmacılara ve uygulayıcılara güncel bilgi sağlaması ve kaynak oluşturması açısından önemli olduğu düşünülmektedir.

$\mathrm{Bu}$ çalışmanın amacı, öğretmen adaylarının öğretmenlik mesleğini seçme nedenlerinin, öğretmenlik mesleğinden beklentilerinin ve öğretmenlik programının niteliğinin artırılmasına yönelik görüşlerinin belirlenmesidir.

$\mathrm{Bu}$ amaç doğrultusunda aşağıdaki sorulara yanıt aranmaktadır;

1. Öğretmen adaylarının öğretmenlik mesleğini seçmelerinde etkili olan unsurlara ilişkin görüşleri nelerdir? 
2. Öğretmen adaylarının öğretmenlik mesleğinden beklentilerini belirleyen unsurlara ilişkin görüşleri nelerdir?

3. Öğretmen eğitim programlarının niteliğinin artırılması konusunda neler yapılabileceğine yönelik öğretmen adaylarının düşünceleri nelerdir?

4. Öğretmen adaylarının ikinci bir tercih yapma şansları olması durumunda, tercih edebilecekleri meslekler nelerdir?

Öğretmen adaylarının öğretmenlik mesleğini seçmelerinde etkili olan unsurlara ilişkin görüşlerinin belirlenmesindeki temel amaç, öğretmen adaylarının öğretmenlik mesleğini seçmelerinde hangi motivasyon unsurlarının etkili olduğunun ortaya çıkarılmasıdır. Öğretmen adaylarının öğretmenlik mesleğinden beklentilerini belirleyen unsurlara ilişkin görüşlerinin belirlenmesindeki temel amaç öğretmen adaylarının hangi beklentiler içerisinde mesleği seçtiğinin ortaya çıkarılmasıdır. Öğretmenlik programının niteliğinin artırılması konusunda neler yapılabileceğine yönelik öğretmen adaylarının düşüncelerinin alınmasındaki temel amaç öğretmenlerin bu konu hakkındaki düşüncelerinin ortaya çıkarılmasıdır. Öğretmen adaylarının ikinci bir tercih yapma şansları olması durumunda, tercih edebilecekleri meslekler nelerdir sorusundaki temel amaç ise öğretmen adaylarının öğretmenlik mesleğine yönelik motivasyonları ile ilgilidir. Mesleğini içsel ve özgeci motivasyonlar doğrultusunda seçen öğretmenlerin mesleğini değiştirmek istememesi, dışsal motivasyon ile seçen öğretmenlerin ise farklı bir meslek seçmesi beklenmektedir.

\section{Yöntem}

Araştırmanın bu bölümünde, araştırmanın modeli, katılımcılar, veri toplama aracı ve verilerin analizi sırası ile sunulmaktadır.

\section{Araştırma Modeli}

Araştırma nitel araştırma desenlerinden durum çalışmasına uygun olarak yürütülmüştür. Nitel araştırma, gözlemlenmek istenilen olguların doğal ortamında gözlemlenerek, gözlem sonucunun çarpıtılmadan, olduğu gibi bütüncül şekilde ortaya koymayı amaçlayan araştırma türüdür (Yıldırım, 1999). Durum çalışmaları ise belirli bir durumun derinlemesine incelendiği çalışmalardır. Bu sayede durumu ortaya çıkaran etkenler bütüncül bir şekilde incelenerek sonuca ulaşılır (Yıldırım ve Şimşek, 2013). Durum çalışmaları belirlenen bir olaya veya duruma odaklanır. Daha sonra elde edilen bulgular yoğun bir şekilde incelenerek durum veya olay açılanır (Merriam \& Grenier, 2019). Bu çalışmada da oluşturulan araştırma sorularının incelenmesi ve katılımcı görüşlerinin ortaya çıkarılması için durum çalışmasından faydalanılmıştır.

\section{Katılımcilar}

Bu araştırmanın katılımcıları 2020-2021 eğitim öğretim yılında eğitim fakültesinde eğitim gören 23 öğretmen adayı oluşturmaktadır. Öğretmen adayları sınıf öğretmenliği, Türkçe eğitimi ve matematik eğitimi anabilim dalında eğitim görmektedirler. Katılımcılardan toplanan veriler kendisini tekrar 
etmeye başladığı zaman veri toplama işlemine son verilir (Creswell, 2013). Bu doğrultuda verilerin tekrar etmeye kanaat getirildiğinde veri toplama işlemi sonlandırılmıştır. Katılımcılar amaçlı örnekleme yöntemlerinden kolay ulaşılabilir örnekleme yöntemi ile belirlenmiştir. $\mathrm{Bu}$ örnekleme yönteminde araştırmaya ulaşılması daha kolay ve hızlı olan katılımcılar dâhil edilmektedir (Patton, 2005). Araştırma katılımcılarının \%52.2'si erkek $(n=12)$, \%47.8'i ise kadındır $(n=11)$. Ayrıca katılımciların \%26.1'i 1. sinıfta $(n=6), \% 21.7$ 'si 2. sinıfta $(n=5), \% 26.1$ 'i 3. sinifta $(n=6)$ sinıfta ve $\% 26.1$ 'i 4. sınıfta ( $n=6)$ eğitim görmektedir.

\section{Veri Toplama Aracı}

Çalışmada veri toplama aracı olarak araştırmacı tarafından oluşturulan yarı yapılandırılmış görüşme formu kullanılmıştır. Yarı yapılandırılmış görüşme formu dört sorudan oluşmaktadır. Oluşturulan soruların amaca ve dil kurallarına uygunluğunu değerlendirmek için alanında uzman 3 kişinin görüşüne başvurulmuştur (ikisi eğitim bilimleri, biri dil bilimleri alanlarından). Uzmanlardan alınan dönütler sayesinde yarı yapılandırılmış görüşme formuna son hali verilmiştir. Böylece çalışmanın iç geçerliğinin sağlanması amaçlanmıştır (Yıldırım ve Şimşek, 2013). Araştırmacı tarafından hazırlanan yarı yapılandırılmış görüşme formunun amaca hizmet edip etmediğinin belirlenmesi, uygulamaya geçilmeden önce çıkabilecek sorunların önceden tespit edilmesi ve tahmin edilemeyen olumsuz durumların belirlenmesi için iki katılımcı ile pilot uygulama yapılmıştır. Uygulama sonucunda verilen cevaplar değerlendirilerek asıl uygulamaya geçilmiş̧ir.

\section{Verilerin Toplanması ve Veri Analizi}

Veriler 15 Mayıs - 10 Haziran 2021 tarihleri arasında toplanmıştır. Hazırlanan yarı yapılandırılmış görüşme formunda araştırmanın önemi, kapsamı ve görüşme formunun nasıl doldurulacağına ilişkin bilgiler verilmiştir. Araştırmada gönüllülük ilkesi doğrultusunda veriler toplanmıştır. Toplanan verileri ilk olarak Word belgesi olarak bilgisayara aktarılmış ve NVivo 10 nitel analiz programı ile "içerik analizi” yapılmıştır. İçerik analizinde temel amaç birbirine benzeyen ifadeleri belirli kavramlar ve temalar doğrultusunda bir araya getirmek ve bu kavram ve temaları okuyucunun anlayabileceği şekilde yorumlamaktır (Yıldırım \& Şimşek, 2013). İçerik analizi sonucunda her bir araştırma sorusu için ayrı tablo oluşturulmuştur. Kategorilere ve alt kategorilere ilişkin verilen örnek ifadeler kodlama sistemi ile sıralanmıştır. Örneğin P1 kodlaması birinci katılımcıyı ifade etmektedir. Katılımcılar kategorilere veya alt kategorilere birden fazla görüş belirtmişlerdir.

Nitel araştırma yöntemlerinde uzman görüşü ve katılımcı teyidi ile geçerliğin sağlanabileceği, teyit incelemesi ile de güvenirliğin sağlanabileceği ifade edilmektedir (Yıldırım ve Şimşek, 2013). Bu bağlamda katılımcılardan toplanan veriler Word ortamına aktarıldıktan sonra katılımcılara tekrar ulaşılmış, ifadeleri okumaları istenmiş ve teyitleri alınmıştır. Bu işlem sonucunda çalışmanın geçerliğinin sağlanması amaçlanmıştır. Çalışmanın güvenirliğinin sağlanması amacıyla veriler eğitim bilimleri alanından bir kişi ve araştırmacı tarafından ayrı ayrı incelenmiştir ve temalar, 
kategoriler ve alt kategoriler oluşturulmuştur. Daha sonra elde edilen temaların, kategorilerin ve alt kategorilerin tutarlıkları karşılaştırılmıştır. Elde edilen temalar, öğretmen adaylarının öğretmenlik mesleğini seçme motivasyonları, öğretmen adaylarının öğretmenlik mesleğinden beklentilerini belirleyen unsurlar olarak belirlenmiştir. Ayrıca öğretmen eğitim programlarının niteliğinin artırılmasına yönelik alt kategoriler elde edilmiştir. Son olarak öğretmen adaylarının ikinci bir tercih yapma şansları olması durumunda tercih edebilecekleri meslekler incelenmiştir.

\section{Bulgular}

$\mathrm{Bu}$ kısımda katılımcılardan toplanan veriler, araştırma soruları doğrultusunda sırasıyla incelenmektedir.

\section{1- Öğretmen Adaylarının Öğretmenlik Mesleğini Seçme Nedenlerine İlişkin Çözümlemeler}

Katılımcıların öğretmenlik mesleğini seçme nedenlerine ilişkin görüşlerinin çözümlenmesi sonucunda Tablo 1 oluşturulmuştur. Ayrıca katılımcıların öğretmenlik mesleğini seçme nedenlerine ilişkin görüşleri, ilgili kategori altında doğrudan alıntılanarak örneklendirilmiştir.

Tablo 1. Öğretmen Adaylarının Öğretmenlik Mesleğini Seçme Nedenlerine İlişkin Tema ve Kategoriler

\begin{tabular}{|c|c|c|c|}
\hline Ana Tema & Alt Tema & Kategoriler & Frekans \\
\hline & & Rahat Çalışma Ortamı & 16 \\
\hline & & Daha Fazla Tatil & 12 \\
\hline & & Düzenli Gelir & 10 \\
\hline & Dişsal Sebepler & Saygın Bir Meslek Olması & 8 \\
\hline & & İş Garantisi & 7 \\
\hline & & Öğretmenlik Giriş Puanı & 5 \\
\hline Öğretmen & & Tavsiye & 3 \\
\hline Adaylarının & & İnsalığa Hizmet Etme & 15 \\
\hline Meslek & Özgeci Sebepler & Rol Model Olma & 11 \\
\hline Seçme & & İnsanların Hayatına Dokunma & 11 \\
\hline \multirow[t]{7}{*}{ Motivasyonları } & & Hayat Boyu Öğrenme & 10 \\
\hline & & Öğretmeyi Sevme & 9 \\
\hline & & İletişim Kurmayı Sevme & 6 \\
\hline & İçsel Sebepler & İdealimdeki Meslek & 5 \\
\hline & & Öğretmenlerin Örnek Olması & 5 \\
\hline & & Çocukları Sevme & 4 \\
\hline & & Okul Ortamını Sevme & 2 \\
\hline
\end{tabular}


Tablo 1'de görüldüğü üzere öğretmen adaylarının meslek seçme motivasyonları ana teması ve dışsal sebepler, özgeci sebepler ve içsel sebepler alt temaları elde edilmiştir. Oluşturulan ana tema, alt temalar ve bu alt temalara ilişkin kategorilere ait ifadelere aşağıda yer verilmektedir.

Dışsal sebepler: Çalışma gurubunda bulunan öğretmen adaylarının bir kısmı öğretmenliği seçme nedenlerini dışsal sebepler ile bağdaştırmaktadır. Bu alt tema içerisinde yer alan kategorilere ilişkin katılımcı görüşleri aşağıda örneklendirilmiştir.

- Rahat çalışma ortamı: Öğretmen adaylarının öğretmenlik mesleğini seçme nedenlerine ilişkin en fazla yüklemenin "rahat çalışma ortamı" kategorisine yapıldığı tespit edilmiştir. Diğer bir ifade ile öğretmen adayları, öğretmenlik mesleğini, rahat çalışma ortamının bulunmasından dolayı tercih etmektedirler. Bu kategoriye ilişkin bazı görüşler aşağıda örneklendirilmiştir.

“...diğer birçok meslek ile klyaslandığında okuldaki çalışma ortamının rahat ve temiz olması önemli bir etken. Ayrıca okulda çalışacağım kişiler belirli bir eğitime düzeyine sahip olan kişiler olacak. Bundan dolayı iletiş̧im kurmanın da rahat olacă̆ı rahat bir ortam olacak... (P2)"

“...okul ortamı çalışmak için rahat. Bize düşen bu rahat ortamda öğrenciler için ne yapacă̆ımız konusunda çalışmak...(P7)”

“...öğretmenliğin rahat bir ortamda yapılması benim için tercih sebebi oldu. Bu durum öğretmenlerin sadece işine odaklanmasını să̆glyor... (P15)”

- Daha fazla tatil: Öğretmen adayları tarafından yüklemenin en fazla olduğu kategorilerden birisi "daha fazla tatil” kategorisidir. Öğretmen adayları, öğretmenlik mesleğinin daha fazla tatili olduğu için tercih etmektedirler. Bu kategoriye referans olabilecek bazı görüşler aşağıda sunulmaktadır.

“...öğretmenlik mesleğinin diğer mesleklere göre daha fazla tatili var. Yazın daha uzun tatil yapabilirim. Kendime daha fazla zaman ayırabilirim. Bu durum öğretmenliği diğer mesleklere göre daha çekici kıllyor... Öğretmenlik mesleğinin seçmemdeki etkenlerden birisi fazla tatili olmast... (P3)"

“...en fazla tatil yapan meslek ögretmenlik. Bundan dolayl fazla yorulmadan para kazanabilirim. Ayrica ailemle daha fazla ilgilenebilirim ... (P11)"

- Düzenli gelir: Katılımcıların görüşleri doğrultusunda elde edilen diğer bir kategori ise "düzenli gelir” kategorisidir. Diğer bir ifadeyle katılımcılar öğretmenlik mesleğini düzenli gelire sahip olmak için seçmektedir. Bu kategoriye referans olabilecek katılımcı görüşü aşağıdaki gibidir.

“...düzenli olarak maaşım yatar, gelecek planlarımı maaşıma göre planlayabilirim. Bu durum mesleğin çekici olmasının ve tercih etmemdeki nedenlerden birisi. (P13)”

- Saygın bir meslek olması: Katılımcı gurupta yer alan önemli bir kesim tarafından ifade edilen diğer bir kategori "saygın bir meslek olması" dır. Diğer bir ifade ile öğretmen adayları öğretmenlik mesleğini saygın bir meslek olduğu için tercih etmektedir. İlgili kategoriyi “...öğretmenlik toplum tarafından saygı gösterilen bir meslektir. Neticede ülkenin geleceğinde öğretmenler söz sahibidir... (P5) " görüşü temsil etmektedir. 
- İş garantisi: Katılımcı görüşleri doğrultusunda elde edilen diğer bir kategori ise "iş garantisi” "dir. Farklı bir ifade ile öğretmen adayları öğretmenlik mesleğini iş garantisi olduğu için seçmektedir. Bu kategoriye ilişkin “...ögretmenliğe atandıktan sonra garanti bir meslek. Devamlı olarak çalışabileceğim bir meslek. Emekli olana kadar çalışabilirim... (P17)” görüşü örnek olarak verilebilir.

- Öğretmenlik giriş puant: Nitel analiz sonucunda elde edilen diğer bir kategori "öğretmenlik giriş puanı” kategorisidir. Öğretmen adaylarının bir kısmı sınav puanlarının öğretmenlik giriş puanına yettiği için bu mesleği seçtiklerini belirtmektedir. Bu kategoriye referans olabilecek görüşlerden bazıları aşağıda örneklendirilmiştir.

"puanım ancak öğretmenlik programına yetiyordu. Bundan dolayı öğretmenlik mesleğini seçtim. Yüksek puan alsaydım büyük bir ihtimalle başka bölümü tercih edecektim (P18)"” "puanım yettiği için ögrretmenlik mesleğini seçtim. Benim için özel bir sebebi yok. (P19)"

- Tavsiye: Öğretmenlik mesleğinin seçilmesi noktasında bir kişinin görüşü doğrultusunda "tavsiye" kategorisi elde edilmiştir. Öğretmen adayları öğretmenlik mesleğini tavsiye sonucunda seçtiğini ifade etmektedir. Bu kategoriyi “...yakın çevremdeki tanıdıklarımın ve akrabalarımın birçoğu öğretmenlik yapıyor. Onlarla konuştuğumda benim için en uygun mesleğin öğretmenlik olduğu söylüyorlardı. Öğretmenlik mesleğinin pozitif yönlerini bana yıllarca anlattılar. Öğretmenlik mesleğini küçüklüğümden beri aklıma kazıdılar... (P23) "ifadesi açıklamaktadır.

Özgeci sebepler: Çalışma gurubunda bulunan öğretmen adaylarının bir kısmı öğretmenliği seçme nedenlerini özgecil sebepler ile bağdaştırmaktadır. Bu alt tema içerisinde yer alan kategorilere ilişkin katılımcı görüşleri aşağıda örneklendirilmiştir.

- Insanlı̆̆a hizmet etme: Öğretmen adaylarının görüşleri incelendiğinde en fazla yüklemenin “insanlığa hizmet etme” kategorisine yapıldığı görülmektedir. Yani öğretmen adayları insanlığa hizmet etmek için öğretmenlik mesleğini tercih ettikleri söylenebilir. Bu kategoriye referans olabilecek bazı görüşler aşağıda örneklendirilmiştir.

“...öğrencilerin yetiştirilmesi çok önemli bir husustur. Geleceğin öğretmenleri, bilim adamları, yöneticileri yetiştirdiğimiz öğrenciler arasından çıkacak. Bu kişilerinde insanlı̆̆ın gelişimi adına önemli katkıları bulunacaktır... (P16)”

“...ögrretmen olursam kendimi hayat boyu geliştirmeyi ve ögrencileri en iyi şekilde eğitmeyi hayal ediyorum. Yani donanıml bireyler yetiştirmek en önemli hayalim. Eğitime katkıda bulunup daha iyi seviyelere gelmesi için ögretmenlik mesleğini tercih ettim ... (P9)”

- Rol model olma: Öğretmen adaylarının görüşlerine göre öğretmenlik mesleğini seçme nedenlerine ilişkin olarak "rol model olma" kategorisi elde edilmiştir. Farklı bir ifade ile öğretmen adayları öğrencilere ve çevresindekilere rol model olabilmek için öğretmenlik mesleğini tercih etmektedir. $\mathrm{Bu}$ kategoriye referans olabilecek görüşlerden ikisine aşağıda yer verilmiştir. 
“...öğretmenlerimin bana rol model olması sayesinde ben bu mesleği seçtim. Ben de ögrencilerime ve çevremdekilere rol model olmak istiyorum. Öğretmenlik mesleğinin prestijini yükseltebilmek için mesleğe uygun bir şekilde davranmam gerekiyor ...(P4)”

“...çevremde öğretmenler rol model olarak gösterilir. Herkes bir konu hakkında fikir almak istiyorsa öğretmen tanıdı̆̆ına sorar. Bundan dolayı herkesin öğretmenlere bakış açısı farklıdır. Bu yüzden ben de öğretmenliği tercih ettim (PI)"

- Insanların hayatına dokunma: Katılımcılar tarafindan görüş bildirilen kategorilerden birisi de "insanların hayatına dokunma" "dır. Öğretmen adayları öğrencilerin hayatına dokunmak için öğretmenlik mesleğini tercih etmektedir. Bu kategoriye referans olabilecek görüşler aşağıda örneklendirilmiştir.

“...gelecekte öğretmen, doktor, mühendis olacak öğrencilerin hayatında bir iz birakmak, onların yetişmesine katkıda bulunmak için öğretmenlik mesleğini tercih ettim... (P16)”

“...hayatının bir bölümünde insanların yanında olmanın, onlara yardım etmenin, onlarla ilgilenmenin çok güzel bir duygu olduğunu düşünüyorum ... (P10)”,

İçsel sebepler: Çalışma gurubunda bulunan öğretmen adaylarının bir kısmı öğretmenliği seçme nedenlerini içsel sebepler ile bağdaştırmaktadır. Bu alt tema içerisinde yer alan kategorilere ilişkin katılımcı görüşleri aşağıda örneklendirilmiştir.

- Hayat boyu öğrenme: İçerik analizi sonucunda en fazla atıf yapılan kategorilerden birisinin "hayat boyu öğrenme" olduğu tespit edilmiştir. Bu bağlamda katılımcılar öğretmenlik mesleğini hayat boyu öğrenme faktöründen dolayı seçmişlerdir. Bu kategoriye referans olan görüşlerden ikisi aşağıda örneklendirilmiştir.

“...çağın gerisinde kalmak istemiyorum, bu yüzden kendimi geliştirmem ve yeni şeyler öğrenmem gerekiyor. Bu yüzden öğretmenlik mesleğinin tam olarak bana uygun olabileceğini düşündüm. Kendimi ve ögrencilerimi geleceğe iyi hazırlamam gerekiyor... (P14)"

"sürekli gelişsim odakl bir kişiliğim var. Yeniliği ve yeni şeyleri seviyorum. Öğretmenlik de sürekli araştırmayı ve gelişmeyi içerisinde barındırıyor. Benim için uygun bir meslek...(P9)"

- Öğretmeyi sevme: Katılımcılar tarafindan öğretmenlik mesleğini seçme nedenleri arasında elde edilen diğer bir kategori "öğretmeyi sevme” kategorisidir. Öğretmen adayları öğretmeyi sevdikleri için öğretmenlik mesleğini tercih etmektedir. Bu kategoriye referans olan görüşlerden bazıları şu şekildedir.

“öğrendiğim şeyleri etrafimdakilere öğretmeyi çok seviyorum. Öğretme işini gerçekleştirirken kendiliğimden konsantre oluyorum ve bu işin sonunda mutlu oluyorum. Bir şeyleri ögrrenme ve onlarl ögretmen benim için ideal bir durum... (P5)",

“...sürekli olarak bir şeyler okuyup, öğreniyorum. Bu öğrendiklerim kendimde saklı kalmasının kimseye bir faydası olacağını düşünmüyorum. Öğrettiklerimi başka kişilere ve ögrencilere ögretmek bana mutluluk veriyor ... (P17)" 
- Iletişim kurmayı sevme: Katılımcıların önemli bir kısmının görüşleri doğrultusunda "iletişim kurmayı sevme" kategorisi elde edilmiştir. Diğer bir ifade ile öğretmen adayları öğretmenlik mesleğini iletişim kurmayı sevdikleri için tercih etmektedirler. Bu kategoriyi “...insanlarla iletişim kurmayı seviyorum. İletişim yönümün kuvvetli olduğunu düşünüyorum. Öğretmenlik mesleği de sürekli olarak iletişim gerektiriyor. Bundan dolayı öğretmenlik mesleğinde başarılı olabileceğimi düşünüyorum (P5)" görüşü temsil etmektedir.

- Ídealimdeki meslek: Katılımcıların ifadeleri doğrultusunda elde edilen kategorilerden birisi de “idealimdeki meslek” dir. Bu kategoriyi “ çocukluğumdan beri hep öğretmen olmak istedim. Neyden etkilendim tam olarak bilmiyorum ama öğretmenlik benim hep idealimdeki meslek oldu... (P6)" görüşü örneklendirmektedir.

- Öğretmenlerimin örnek olması: Öğretmen adaylarının görüşlerine göre "öğretmenlerin örnek olması" kategorisi elde edilmiştir. Öğretmen adayları, öğretmenlerinin kendilerine örnek olmalarının öğretmen seçimlerinde etkili olduğunu belirtmektedir. Bu kategoriyi “...eğitim hayatım boyunca birçok öğretmenim oldu. Bu öğretmenler arasında gerek davranışlarıyla gerekse iletişim şekli ile beni destekleyen ve bu mesleği sevdiren öğretmenlerim oldu. Onlar sayesinde öğretmen olmanın benim için daha uygun olabileceğini düşündüm (P4)" ifadesi örneklendirmektedir.

- Çocukları sevme: Verilerin analizi sonucunda elde edilen diğer bir kategori ise "çocukları sevme" dir. Bu kategoriye “...çocuklarla ilgilenmek her zaman benim için eğlenceli bir iş olmuştur. Çocuklarla ilgilenirken resmen ben de çocuk olabiliyorum. Onların seviyesine inip onların düşündüğü gibi düşünüyorum. Onlarla ilgilenmeyi seviyorum... (P10)” görüşü örnek olarak gösterilebilir.

- Okul ortamını sevme: Öğretmenlerin meslek seçme motivasyonlarına yönelik son kategori ise “okul ortamını sevme” “dir. Yani öğretmen adayları okul ortamını sevdikleri için öğretmenlik mesleğini tercih etmektedir. Bu kategori için belirtilen görüşleri “...okuldaki öğrenme ortamı yıllarca içerisinden bulunduğumuz bir ortam. Bu ortam bana huzur veriyor. Kendimi okul ortamında daha verimli hissediyorum. Bu ortamda daha faydalı olabileceğimi düşünüyorum... (P14)" görüşü örnek olarak verilebilir.

\section{2- Öğretmen Adaylarının Öğretmenlik Mesleğinden Beklentilerine İlişkin Çözümlemeler}

Öğretmen adaylarının öğretmenlik mesleğinden beklentilerine ilişkin bir ana tema ve üç alt tema oluşturulmuştur. Alt temalar mesleki beklenti, sosyal beklenti ve ekonomik beklenti olarak isimlendirilmiştir. Tablo 2'de görüldüğü gibi en fazla mesleki beklentiler alt temasına, ikinci olarak sosyal beklentiler alt temasına ve son olarak ekonomik beklentiler alt temasına atıf yapılmıştır. Ayrıca alt temalara ilişkin kategoriler oluşturulmuştur. 
Tablo 2. Öğretmenlik Mesleğinden Beklentilere İlişkin Tema ve Kategoriler

\begin{tabular}{lllc}
\hline \multicolumn{1}{c}{ Ana Tema } & \multicolumn{1}{c}{ Alt Tema } & Kategoriler & Frekans \\
\hline & & Mesleki Gelişim & 17 \\
& \multirow{3}{*}{ Mesleki Beklentiler } & Çalışma Ortamı & 17 \\
& & Akademik İlerleme & 14 \\
Meslekten & & Donanımlı Gençler Yetiştirme & 9 \\
Gelecek & & Mesleği Sevme & 8 \\
Beklentisi & \multirow{2}{*}{ Sosyal Beklentiler } & Geleceği Şekillendirme & 12 \\
& & Sosyal Statü & 10 \\
& & Sağlılı İletişim & 6 \\
\cline { 2 - 4 } & \multirow{2}{*}{ Ekonomik Beklentiler } & Maaş Beklentisi & 6 \\
& & Ek İndirimler & 3 \\
\hline
\end{tabular}

Tablo 2'de görüldüğü üzere meslekten gelecek beklentisi ana temas1 ve mesleki beklentiler, sosyal beklentiler ve ekonomik beklentiler alt temaları elde edilmiştir. Oluşturulan ana tema, alt temalar ve bu alt temalara ilişkin kategorilere ait ifadelere aşağıda yer verilmektedir.

Mesleki beklentiler: Çalışma gurubunda bulunan öğretmen adaylarının büyük bir çoğunluğunun öğretmenlik mesleğinden mesleki olarak beklentileri olduğu sonucuna ulaşılmaktadır. Bu alt tema içerisinde yer alan kategorilere ilişkin belirtilen bazı görüşler aşağıda örneklendirilmiştir.

- Mesleki gelişim: Öğretmen adaylarının öğretmenlik mesleğinden beklentilerine ilişkin en fazla yüklemenin "mesleki gelişim" kategorisine yapıldığı tespit edilmiştir. Öğretmen adayları öğretmenlik mesleğinde mesleki olarak kendilerini geliştirme beklentisi içerisindedir. Bu kategoriye ilişkin katılımcı görüşlerinin bazıları aşağıda sunulmaktadır.

"öğretmenlik mesleğine atandıktan sonra alanımda kendimi geliştirmek ve yetkin bir ögretmen olmak istiyorum. Beklentilerimin başında kendi gelişimin sağlanması gelmektedir... (P9)",

“...öğrencilere ögreteceğim konulara hâkim olmam gerekiyor. Bundan dolayı bu konuları derinlemesine öğrenip kendimi geliştirmek beklentilerimin başında geliyor. Mesleğimin ilk yıllarından başlayarak sürekli kendimi geliştirmek için çalışacağım ... (P14)”

"ögrencilere faydalı olabilmem için ve onların gelişiminin tam olarak sağlanması için kendimi alanımda yetiştirmem gerekiyor. Ayrıca değişen dünyada kendimi sürekli yenilemem gerekiyor. Bilgi sürekli değişsiği için yeni bilgiler elde edilmesi önemlidir... (P7)”

- Çalışma ortamı: Katılımcılar tarafından en fazla yükleme yapılan kategorilerden ikincisi "çalışma ortamı" kategorisidir. Katılımcıların okullarda çalışma ortamına yönelik beklentileri bulunmaktadır. Bu kategoriye referans olabilecek katılımcı görüşleri aşağıdaki gibidir. 
M.Y. Kılıç/ Pamukkale Üniversitesi Eğitim Fakültesi Dergisi, 56, 35-65, 2022

"okulda çalışma ortamının huzurlu olmasını bekliyorum. Öğretmenlerin beklentilerini

karşılayacak olumlu bir okul ortamı öğretmenlerin ve öğrencilerin faydasına olacaktır... (P14)”

"çalıştığım ortamın destekleyici bir iklime sahip olması gerekiyor. Herkesin birbirine yardımcı olduğu bir ortamda çalışmak daha verimli bir eğitimin gerçekleşmesini sağlar. Verimli bir ortama sahip okulda çalışmak istiyorum ... (P6)"

- Akademik ilerleme: Öğretmen adaylarının önemli bir kısmının "akademik ilerleme" kategorisine atıf yaptığı sonucuna ulaşılmıştır. Öğretmen adaylarının öğretmenlikte akademik olarak ilerleme beklentileri bulunmaktadır. Bu kategoriyi "öğretmen olduktan sonra akademik olarak ilerlemek istiyorum. Okul yönetiminde görev almak istiyorum. Okul müdürlüğü tecrübesini yaşamak istiyorum... (P17)" görüşü temsil etmektedir.

- Donanımlı öğrenciler yetiştirme: Katılımcıların belirttikleri görüşler doğrultusunda "donanımlı öğrenciler yetiştirme” kategorisi elde edilmiştir. Bu kategoriyi “...öğrencilerin mezun olurken donanımlı bir şekilde mezun olması gerekiyor. Bunun sağlanabilmesi için gerekli olan kazanımların öğrencilere kazandırılması gerekiyor. Gerekli becerileri kazanmış şekilde mezun olmaları en büyük beklentim... (P10)" görüşü örneklendirmektedir.

- Mesleği sevme: İçerik analizi sonucunda elde edilen diğer kategori ise "mesleği sevme" 'dir. Bu kategoriye "...mesleği isteyerek seçmedim, bundan dolayı ileride mesleği sevip en iyi şekilde gerekliliklerini yerine getirmek istiyorum... (P23)" görüşü örnek olarak verilebilir.

Sosyal beklentiler: Öğretmen adaylarının bir kısmının öğretmenlik mesleğinden sosyal beklentilerinin olduğu sonucuna ulaşılmıştır. $\mathrm{Bu}$ alt tema içerisinde bulunan kategorilere ilişkin bazı ifadeler aşağıda örneklendirilmektedir.

- Geleceği şekillendirme: Öğretmen adaylarının görüşleri doğrultsusunda "geleceği şekillendirme" kategorisi elde edilmiştir. Bu durumda öğretmen adaylarının geleceği şekillendirme beklentisi içerisinde oldukları söylenebilir. Bu kategoriye referans olabilecek görüşlerden bazıları aşagıdaki gibidir.

“...ülkenin geleceğinde söz sahibi olacak gençlerin yetiştirilmesi ve niteliklerinin artırılmasında görev almak güzel olur diye düşünüyorum. Geçlerin yetiştirilmesine katkıda bulunmak en büyük beklentim... (P15)”

“öğrencilerin ve toplumun beklentilerini karşllamak kendi beklentilerim ile örtüşmektedir... (P13)"

- Sosyal statü: Yapılan analiz sonucunda "sosyal statü” kategorisi elde edilmiştir. Öğretmen adayları öğretmenlik mesleğinden kendilerine sosyal statü kazandırmasını beklemektedir. Bu kategoriye referans olabilecek görüşlerden bazılarına aşağıda yer verilmektedir.

“...öğretmenlik mesleğinin saygın bir meslek olduğunu düşünüyorum. İleride toplum içerisine girdiğimde saygın bir kişilik olarak gösterilebileceğimi hayal ediyorum...(P10)” 
"Öğretmenliğin sorumlulukları diğer mesleklerden fazladır. Bu da öğretmenlik mesleğinin

bütün toplum üzerindeki etkisinden kaynaklanır. Öğretmenliğin sosyal yaşamda bana değer katacă̆ını düşünüyorum... (P14)"

- Sağlıklı iletişim: İçerik analizi sonucunda elde edilen kategorilerden birisi de "sağlıklı iletişim" 'dir. Bu kategoriye “...özellikle okul ortamında sağlıklı iletişim kurabileceğim bir ortamın olması beklentilerimden birisidir. Herkesin kendini rahat ve özgür ifade edebilmesi anlaşmazlıklar çözer... (P16)" görüşü örnek olarak gösterilebilir.

Ekonomik beklentiler: Araştırma katılımcılarının az bir kısmı öğretmenlik mesleğinden ekonomik beklentilerinin olduğunu ifade etmektedir. Bu alt tema doğrultusunda oluşturulan kategorilere ilişkin örnek ifadeler aşağıda örneklendirilmiştir.

- Maaş beklentisi: Öğretmen adaylarının ifadeleri sonucunda "maaş beklentisi" kategorisi elde edilmiştir. İlgili kategoriye ilişkin ortaya konulan görüşleri “ “...hem kendim hem de ailemin rahat bir yaşantı sürebilmesi için düzenli bir maaş almam gerekiyor. Öğretmenlik mesleği düzenli maaş almamda bir araç olabilir... (P23)" ifadesi temsil etmektedir.

- Ek indirimler: Öğretmen adaylarının öğretmenlik mesleğinden beklentilerinden birisi ise "ek indirimler” 'dir. Bu kategoriyi “...öğretmenler için teşvik edici ek indirimler sağlanması beklentisindeyim. Özellikle kitap, bilgisayar gibi birçok ürünlerde ek indirim sağlanması öğretmenleri daha çok motive edebilir... (P22)" görüşü örneklendirmektedir.

\section{3- Öğretmen Adaylarının Öğretmen Eğitim Programlarının Niteliğinin Artırılmasına Yönelik Görüşlerine İlişkin Çözümlemeler}

Araştırma katılımcılarının öğretmen eğitim programlarının niteliğinin artırılmasına yönelik görüşleri sonucunda Tablo 3 oluşturulmuştur. Tablo 3'de öğretmen adaylarının öğretmen eğitim programlarının niteliğinin artırılmasına yönelik görüşleri doğrultusunda oluşturulan kategori ve alt kategoriler verilmektedir.

Tablo 3. Öğretmen Ĕgitim Programlarının Niteliğinin Artırllmasına Yönelik Kategori ve Alt Kategoriler

\begin{tabular}{ccc}
\hline Kategori & Alt Kategoriler & Frekans \\
\hline & Öğretim Yöntemi Değiştirilmeli & 16 \\
Öğretmenlik Ĕ̆itim & Giriş Şartları Düzenlenmeli & 12 \\
Programlarının & Öğrenci Sayısı Azaltılmalı & 9 \\
Niteliğinin Artırılması & Tecrübeli Öğretim Elemanı & 7 \\
& Etkili İletişim & 6 \\
& Yeterli Destek & 4 \\
\cline { 2 - 3 } & Fiziki İmkânlar & 2 \\
\hline
\end{tabular}


Tablo 3'de görüldüğü üzere "öğretim yöntemi değiştirilmeli”, "giriş şartları düzenlenmeli”, “öğrenci sayısı azaltılmalı", "tecrübeli öğretim elemanı", "etkili iletişim”, "yeterli destek" ve "fiziki imkânlar" alt kategorileri elde edilmiştir.

Öğretim yöntemi değişstirilmeli: Öğretmen eğitim programlarının niteliğinin artırılmasına ilişkin elde edilen alt kategoriler arasından en fazla yüklemenin “öğretim yöntemi değiştirilmeli” alt kategorisine yapıldığı sonucuna ulaşılmıştır. Katılımcılar öğretmen eğitim programlarının niteliğinin artırılması için öğretim yönteminin değiştirilmesi gerektiğini düşünmektedir. Bu alt kategoriye referans olabilecek görüşlerin bazılarına aşağıda yer verilmektedir.

"derslerin çoğunluğu teorik olarak işleniyor. Pratik olarak işlenmesi ile öğretmen adaylarının daha fazla tecrübe kazanabileceğini ve niteliklerinin artabileceğini düşünüyorum...(P3)”

“...uygulamalı derslerin sayısının artırllmasıyla hiç değilse yaparak yaşayarak öğrenebiliriz. Bu da amaca uygun öğretmen yetişmesine yardımcı olur...(P7)”

"bazı öğretmenler derste bazı ögretim yöntem ve tekniklerini anlatıyor ama o teknikleri yaşayarak öğrenemedikten sonra bir anlamı kalmıyor açıkçası. Mesleğe atandiğımızda daha verimli çalışabilmemiz için üniversitede tecrübe kazanmamız gerek... (P12)”

Giriş şartları düzenlenmeli: Öğretmen eğitim programlarının niteliğinin artırılmasına ilişkin elde edilen görüşler doğrultusunda "giriş şartları düzenlenmeli" alt kategorisi elde edilmiştir. Aşağıda yer alan görüşler bu alt kategoriyi örneklendirmektedir.

“öğretmenliği herkesin yapabileceği bir meslek olarak görmüyorum. Öğretmen olabilmek için bireyin sahip olduğu kişilik özellikleri çok önemli. Öğretmenliğe giriş için çok aşamalı bir giriş sisteminin yapılması daha niteliği artırır...(P10)”

“öğretmenlik özel bir meslek. Belirli kriterlere sahip olmanız gerekmektedir. İletişim becerinizin güçlü olması gerekir. Kendinizi iyi ifade etmeniz gerekir. Sabırlı olmanız gerekir. Öğretmenlik seçiminde bu kriterlerin de dikkate alınarak yeni değerlendirme sistemi getirilmeli... (P16)"

Öğrenci sayısı azaltılmalı: Öğretmen eğitim programlarının niteliğinin artırılması amacıyla toplanan veriler sonucunda "öğrenci sayısı azaltılmalı" kategorisi elde edilmiştir. Bu kategoriye "öğrenci sayısının azaltılması ile daha verimli ve etkili eğitim gerçekleştirilebilir. Bu sayede öğretmenler öğrencilerle bire bir ilgilenebilir ve onların gelişimini takip edebilir (P15)" görüşü örnek olarak gösterilebilir.

Tecrübeli öğretim elemanı: Araştırmaya katılan öğretmen adaylarının bir kısmının görüşü doğrultusunda "tecrübeli öğretim elemanı" kategorisi elde edilmiştir. Katılımcılar tecrübeli öğretim elemanı yetiştirilmesiyle öğretmen eğitim programlarının niteliğinin artabileceğini ifade etmektedir. Bu kategoriye referans olabilecek görüş “...daha tecrübeli öğretim elemanlarının ders vermesi ile niteliğin artırılması sağlanabilir. Tecrübesiz öğretim elemanlarının yetiştirilebilmesi amacıyla daha önemsiz derslerde görev alması sağlanabilir... (P17)” şeklindedir. 
Etkili iletişim: Öğretmen adaylarının bazıları etkili iletişimin öğretmen eğitim programlarının niteliğini artırabileceğini belirtmektedir. Bu kategoriye ilişkin "üniversite hocaları ve öğrenciler arasındaki iletişimin kalitesi niteliği kesinlikle artırır. Bazı hocalar dersini anlatıyor ve gidiyor, gerisi onları ilgilendirmiyor gibi tavır sergiliyor. Hocaların etkili iletişim kurması gerekiyor... (P5)" görüşü örnek olarak verilebilir.

Yeterli destek: Araştırma katılımcıların görüşleri doğrultusunda öğretmen adaylarına yeterli destek sağlanması durumunda öğretmen eğitim programlarının kalitesinin artırılabileceği ifade edilmektedir. Katılımcılardan birisi "öğretmen adaylarına maddi manevi destek sunulması gerekmektedir. Devletin sağlayacağı destek ve teşvikler öğrenim kalitesini artırabilir. Öğrencilerin kendi başına aşamayacağı sıkıntıları olabiliyor. Bunların çözümü için destek sağlanması öğretmen adaylarının motivasyonunu artırır...(P6)"görüşünü ileri sürmüştür.

Fiziki imkânlar: Öğretmen adaylarının ifadeleri doğrultusunda elde edilen diğer bir kategori ise “fiziki imkânlar” kategorisidir. Öğretmen adayları öğretmen eğitim programlarının niteliğinin artırılabilmesi için fiziki imkânların sağlanabilmesi gerektiğini belirtmektedir. Bu kategoriye ilişkin “öğretmen adaylarının fiziki olarak imkânlarının yeterli olması gerekmektedir. Eğitim öğretimde kullanabileceği bütün yöntem ve teknikler için somut imkânların sağlanması gerekir. Ayrıca sosyal imkânların da sağlanması öğretmen adayının kendisini bir bütün olarak geliştirmesine yardımcı olur...(P13)" görüşü örnek olarak verilebilir.

\section{4- Öğretmen Adaylarının İkinci Bir Tercih Yapma Şansları Olması Durumunda Tercih Edebilecekleri Mesleğe Yönelik Görüşlerine İlişkin Çözümlemeler}

Katılımcıların ikinci bir tercih yapma şansları olması durumunda tercih edebilecekleri mesleğe yönelik görüşleri doğrultusunda Tablo 4 oluşturulmuştur. Ayrıca katılımcıların ikinci bir tercih yapma şansları olması durumunda tercih edebilecekleri mesleğe yönelik görüşleri Tablo 4'de gösterilmektedir.

Tablo 4. Öğretmen Adaylarının İkinci Bir Tercih Yapma Şansları Olması Durumunda Tercih Edebilecekleri Mesleğe İlişkin Görüşer

\begin{tabular}{lc}
\hline Meslekler & Frekans \\
\hline Öğretmenlik & 17 \\
Avukat & 2 \\
Sahne Sanatları & 1 \\
Gemicilik & 1 \\
Bilgisayar Mühendisliği & 1 \\
Mimarlık & 1 \\
\hline
\end{tabular}


Öğretmen adayları ikinci bir tercih yapma şansları olması durumunda tercih edebilecekleri mesleğe ilişkin "yeniden öğretmenlik", "avukat", "sahne sanatları", "gemicilik", "bilgisayar mühendisliği” ve "mimarlık" mesleklerinin bildirmişlerdir.

Öğretmenlik: Öğretmen adaylarının ikinci bir tercih yapma şansları olması durumunda tercih edebilecekleri mesleğe ilişkin görüşleri doğrultusunda en fazla ifade "öğretmenlik" dir. Öğretmen adaylarının çoğunluğu tekrar öğretmenlik mesleğini seçeceklerini belirtmiştir. Bu ifadeye referans olabilecek görüşlerden bazılarına aşağıda yer verilmektedir.

“öğretmenlik tercihimden vazgeçeceğimi düşünmüyorum. Öğretmenliği küçüklükten beri istiyordum. İdealimdeki mesleği seçtim zaten... (P6)"

"çocuklarla iletişimin hep iyi olmuştur. Budan dolayı çocuklarla ilgilenmek benim için hep eğlenceli oldu. Bundan dolayı öğretmenlik tercihimden vazgeçmem ...(P10)”

“...kendimi sürekli olarak geliştirmeyi amaçllyorum. Öğretmenlik mesleğinin bunun için uygun bir meslek olduğuna inanıyorum. Bu yüzden büyük ihtimal tercihim değişmezdi...(P14)"

Bunun yanı sıra diğer öğretmen adylarının tercihleri ise "avukat" (P18), "sahne sanatları" (P19), “gemicilik" (P21), "bilgisayar mühendisiliği” (P22) ve "mimarlık” (P23) olmuştur. Katılımcıların öğretmenlik mesleğine yönelik motivasyonlarının yüksek düzeyde olduğu söylenebilir. Çünkü katılımcıların büyük bir çoğunluğu ikinci seçenek olarak da öğretmenlik mesleğini seçebileceklerinin belirtmişlerdir. Bunun yanı sira (P18), (P19), (P21), (P22) ve (P23) farklı meslekleri seçebileceklerini belirtmektedir. Çalışmada elde edilen kategorilere ait görüşler incelendiğinde bu öğretmen adaylarının bazılarının öğretmenlik mesleğini dışsal motivasyon ile tercih ettiği [(P18), (P19), (P21), (P23)] bir öğretmen adayının ise öğretmenlikten maaş beklentisi olduğu (P22) söylenebilir. Sonuç olarak dişsal motivasyon ile öğretmenlik mesleğini tercih eden öğretmen adaylarının, öğretmenlik mesleğine göre motivasyonlarının düşük olduğu sonucuna ulaşılabilir.

\section{Tartışma ve Sonuç}

$\mathrm{Bu}$ araştırmada öğretmen adaylarının öğretmenlik mesleğini seçme nedenleri, öğretmenlik mesleğinden beklentileri ve öğretmenlik programının niteliğinin artırılmasına yönelik görüşleri incelenmiştir. $\mathrm{Bu}$ doğrultuda nitel araştırma soruları oluşturulmuş ve sorulara yanıt aranmıştır. Aşağıda nitel araştırma soruları sırasıyla ele alınıp tartışılmaktadır.

Araştırmadan elde edilen birinci bulguya göre ana tema öğretmen adaylarının meslek seçme motivasyonları olarak adlandırılmıştır. Alt temalar ise dışsal sebepler, özgeci sebepler ve içsel sebepler olmak üzere üç başlık altında toplanmıştır. Dışsal sebepler alt temasında rahat çalışma ortamı, daha fazla tatil, düzenli gelir, saygın bir meslek olması iş garantisi, öğretmenlik giriş puanı ve tavsiye kategorileri bulunmaktadır. Özgeci sebepler alt temasında insanlığa hizmet etme, rol model olma ve insanların hayatına dokunma kategorileri bulunmaktadır. İçsel sebepler alt temasında ise hayat boyu öğrenme, öğretmeyi sevme, iletişim kurmayı sevme, idealimdeki meslek, 
öğretmenlerin örnek olması, çocukları sevme ve okul ortamını sevme kategorileri bulunmaktadır. Bergmark, Lundström, Manderstedt ve Palo (2018) yaptıkları çalışmada öğrencilerin kariyer seçimlerinde içsel, özgecil ve dişsal güdülerin etkili olduğunu ve öğretmenlik mesleğini seçmeleri için birden fazla güdüye sahip oldukları belirtilmektedir. Çermik, Doğan ve Şahin (2010) sınıf öğretmen adaylarının öğretmenlik mesleğini seçme nedenlerinin özgecil, içsel, dışsal ve çıkarcı gerekçelerden etkilendiğini ifade etmektedir. Bunun yanı sıra sınav puanı, aile baskısı, idealindeki meslek olması, iletişim becerileri, saygın bir meslek olması, topluma faydalı olabilme gibi alt temaların elde edildiği görülmektedir. Bu çalışma ile benzer sonuçlar elde edildiği söylenebilir. Benzer bir şekilde Low, Lim, Ch'ng ve Goh (2011) tarafından yapılan çalışmada öğretmen adaylarının öğretmenlik mesleğini seçme nedenleri, özgecil, içsel, dışsal ve diğer nedenler olarak kategorilere ayrılmıştır. Çalışmada rol model olmak ve çocukları sevmek gibi benzer alt temalar elde edilmiştir. Farklı bir çalışmada ise Bursal ve Buldur (2013) öğretmen adaylarının öğretmenlik mesleğini seçme nedenleri konusunda ölçek geliştirmiştir. Yaptığı faktör analiz sonucunda ölçeğin özsel ve dışsal nedenleri olarak ikiye ayrıldığı ve fakat özsel nedenler faktörünün de özgeci ve içsel nedenlerden oluştuğu ifade edilmektedir. Ayrıca ölçek maddelerinde bu çalışmada elde edilen kategorilere benzer ifadeler de bulunmaktadır. Bu bulgular çalışma sonucunu destekler niteliktedir.

Araştırmadan elde edilen bulgular doğrultusunda meslekten gelecek beklentisi ana teması oluşturulmuştur. Alt temalar ise mesleki beklentiler, sosyal beklentiler ve ekonomik beklentiler olarak üç başlık altında toplandığı sonucuna ulaşılmıştır. Mesleki beklentiler alt temasında mesleki gelişim, çalışma ortamı, akademik ilerleme, donanımlı öğrenciler yetiştirme ve mesleği sevme kategorileri bulunmaktadır. Sosyal beklentiler alt temasında geleceği şekillendirme, sosyal statü ve sağlıklı iletişim kategorileri bulunmaktadır. Ekonomik beklentiler alt temasında ise maaş beklentisi ve ek indirimler kategorileri bulunmaktadır. Gömleksiz, Kan ve Biçer (2010) öğretmen adaylarının öğretmenlik mesleğinden beklentilerinin belirlenmesi için ölçek uygulamıştır. Araştırmacılar tarafından geliştirilen ölçek öğretmen adaylarının sosyokültürel, mesleki, maddi ve kariyer beklentisini ölçmek için tasarlanmıştır. Ayrıca ölçek maddeleri incelendiğinde bu çalışmada elde edilen alt temalar ile benzerlik gösterdiği sonucuna ulaşılmıştır. Koşar (2018) yaptığı çalışmada öğretmen adaylarının beklentilerini ekonomik, sosyal, göreve ilişkin, bireysel ve olumsuz beklentiler olarak kategorilere ayırmıştır. Ayrıca ekonomik beklentiler arasında maaş ve geçim sağlama beklentisi, sosyal beklentiler arasında toplumsal statü ve insan ilişkileri, göreve ilişkin beklentiler arasında ise sınıf yönetimi, çalışma ortamı, mesleki gelişim gibi alt faktörler bulunmaktadır. Uras ve Kunt (2006) tarafından yapılan çalışmada öğretmen adaylarının öğretmenlikten beklentileri sosyal, ekonomik, mesleki gelişim ve yasal beklentiler olarak dört alanda ayrı ayrı incelenmiştir. İncikabı, Biber ve Mercimek (2016) tarafından yapılan çalışmada ise öğretmen adaylarının beklentileri mesleki gelişim, akademik gelişim ve sosyal gelişim temaları altında incelenmiştir. Ayrıca en çok 
öne çıkan temanın ise mesleki gelişim teması olduğu belirtilmiştir. Elde edilen bu sonuçlar diğer araştırma sonuçları tarafından desteklenmektedir.

Öğretmen adaylarının beklentileri ve bu beklentilerinin gerçekleşmesi yönünde geliştirdikleri tutum ve davranışlar öğretmen adaylarının motivasyonlarını ve verimliliğini büyük ölçüde etkilemektedir. Öğretmen adaylarının meslekten beklentilerinin gerçekleşmemesi durumunda motivasyonlarının düşeceği ve bu durumda verimin de düşeceği söylenebilir (Uras ve Kunt, 2005). Geleceğin sağlıklı bir şekilde oluşturulmasında öğretmenlerin her açıdan desteklenmesi gerekmektedir. Bunu sağlayabilmek için ise öğretmenlerin meslekten beklentilerinin karşılanması gereklidir (Şahin, 2011). Fakat öğretmen adaylarının mesleğe başlamadan önceki beklentileri ile göreve başladıktan sora karşılaştıkları durumların arasında farklılıkların olduğu söylenmektedir (Yeşilyurt ve Karakuş, 2011). Özellikle ilgili kurumların öğretmenlik mesleğine adım atmış bireylerin mesleki, sosyal ve ekonomik beklentilerini karşılayacak eğitim politikaları oluşturması durumunda, onların mesleğe karşı doyumunu sağlayacaktır. Bu durum ise eğitim sisteminin niteliğinin artırılması adına önemli görülmektedir (Özsarı 2008).

Öğretmen adaylarının görüşleri değerlendirildiğinde öğretmen eğitim programlarının niteliğinin artırılması kategorisi elde edilmiştir. Bu kategori ise öğretim yöntemi değiştirilmeli, giriş şartları düzenlenmeli, öğrenci sayısı azaltılmalı, tecrübeli öğretim elemanı, etkili iletişim, yeterli destek ve fiziki imkânlar alt kategorilerine ayrılmıştır. Elde edilen sonuçlar incelendiğinde öğretmen adayları öğretim yöntemlerinin değiştirilmesi gerektiğini belirtilmektedir. Dolayısıyla Okçabol (2004) çalışmasında öğretmen adaylarının teorik ve uygulamaya yönelik derslerinin yeterli düzeyde olmadığını belirtmektedir. Bunun yanı sıra uygulamaya dayalı derslerin öğretmenlik becerisinin kazandırılması açısından daha etkili olduğu söylenebilir (Şahin ve Kartal, 2013). Çünkü teorik olarak öğrenilen derslerin ancak uygulama ile tecrübe edilmesi durumunda anlamlı hale gelmesi sağlanır (Özkılıç, Bilgin ve Kartal, 2008). Öğretmen adayları öğretmenlik mesleğine giriş şartlarının düzenlenmesi konusunda görüş bildirmişlerdir. Özellikle merkezi sınav uygulamasının öğretmenlik programının niteliğini düşürdüğü söylenebilir. Bu ifadeyi destekler bir şsekilde Can (2019) çalışmasında mesleki gelişimin engelleri arasında merkezi sınav uygulaması olduğunu belirtmektedir. Öğretmen adayları merkezi sınavlardan yüksek başarı elde etme baskısı altında kalmakta ve dolayısıyla öğretmen adayı olarak öğretmenlik niteliklerinin artırılmasından ziyade sınavda çıkabilecek konulara yoğunlaşma eğilimi göstermektedirler (Barnes, 2005). Ayrıca bu durum öğretim programlarının merkezi sınavlara göre şekillendirilmesini sağlamakta ve öğretmen rollerini ikinci plana atmaktadır (Can, 2017; Şahin, Uz Baş, Şahin Fırat, Sucuoğlu, 2012). Bunun yanı sıra öğrenci sayısının azaltılmasının, tecrübeli öğretim elemanı istihdam edilmesinin, etkili iletişimin, yeterli destek ve fiziki imkânlar oluşturmanın eğitimin niteliğini artırabileceği söylenebilir. Yapılan çalışmalar bu bulguları destekler niteliktedir. Öner ve Yılmaz (2019) tarafından yapılan çalışmada uygulamalı derslere önem verilmesi, program şartlarının gözden geçirilmesi, 
öğrenci sayısının azaltılması, öğretim elemanlarının yetkin olması gibi ifadeler elde edilmiştir. $\mathrm{Bu}$ temalar bu çalışmada elde edilen temalar ile benzerlik göstermektedir. Hacettepe Üniversitesi, Eğitim Fakültesi (2017) öğretmen ihtiyacının orta ve uzun vadede planlanması ve kontenjanlarının buna göre belirlenmesinin öğretmenlik programının niteliğini artıracağını ifade etmektedir. Benzer bir şekilde Elma ve Ergen (2016) öğretmenlik eğitiminin niteliğinin artırılması için öğrenci sayısının azaltılması ve bunun yanı sıra öğretmenlerin yeteneklerine göre seçilmesi gerektiğini belirtmektedir.

Araştırma sonucunda öğretmen adaylarının ikinci bir tercih yapma şansları olması durumunda tercih edebilecekleri mesleklere ilişkin görüşler belirlenmiştir. Öğretmen adaylarının büyük bir çoğunluğu tekrar öğretmenlik mesleğini seçeceğini belirtmektedir. Ayrıca avukat, sahne sanatları, gemicilik, bilgisayar mühendisliği ve mimarlık mesleğini seçebileceklerini belirten öğretmen adayları da bulunmaktadır. Bu durum aslında bazı öğretmen adaylarının mesleklerinden memnun olmadığı ve başka mesleklere yönelme niyetlerini ortaya çıkarmaktadır. Ayrıca yeniden öğretmen olurdum diyen öğretmen adaylarının çoğunluğu öğretmenlik mesleğini içsel ve özgeci sebepler ile seçtikleri, diğer meslekleri tercih edebileceklerini belirten öğretmen adaylarının ise öğretmenlik mesleğini dışsal sebeplerle tercih ettikleri söylenebilir. Şahin, Zoraloğlu ve ŞahinFrrat'ın (2011) tarafından yapılan çalışmada öğrencilerin 15.7'sinin okudukları bölümü değiştirmek istediği, \%66,5'inin okuduğu bölümden memnun olduğunu, \%17,8'inin ise kararsız olduğu sonucuna varılmıştır. Okuduğu bölümü değiştirmek isteyen öğrenciler, okuduğu bölümün yeteneklerine uygun olmadığı ve mezun olduğunda rahat iş bulabileceğini düşünmesi gibi sebepler sunmuşlardır. İncelendiğinde bu sebepler daha çok dişsal motivasyonla örtüşmektedir. Dışsal motivasyonla bölümünü tercih eden öğrencilerin bölüm değiştirmek istediği söylenebilir. İçsel ve özgeci nedenlerle mesleği tercih eden bireylerin ise mesleğinden memnun oldukları çıkarımında bulunabilir. Dolayısıyla Buldur ve Bursal (2015) yaptığı çalışmada ideal mesleği öğretmenlik olan bireylerin, mesleğinin tercih nedenlerinin içsel ve özgeci sebepler olduğunu belirtmektedir. Ayrıca içsel ve özgeci sebeplerle mesleğini seçen öğretmenlerin gelecek beklentilerinin daha olumlu olduğu söylenmektedir. İçsel sebeplerle mesleğini seçen bireylerin mesleklerine karşı tutumlarının daha olumlu olduğu (Bozdoğan, Aydın ve Yıldırım, 2007; Watt ve Richardson, 2008), dışsal nedenlerle meslekleri seçen bireylerinin ise gelecek beklentilerinin düşük olduğu (Beşoluk ve Horzum, 2011; Çermik, Doğan ve Şahin, 2010) söylenebilir. Ayrıca içsel nedenlerle öğretmenlik mesleğini seçen bireylerin işlerinden memnun oldukları ve zevk aldıkları, mesleklerini severek yaptıkları ve başarılı oldukları belirtilmektedir (Özkubat ve Demiriz, 2013). Herzberg'in çift faktör kuramı incelendiğinde içsel faktörlerin çalışanlar üzerinde yüksek motivasyon oluşturuduğu, dişsal motivasyonun ise motive etmede uygun bir ortam oluşturmadığı söylenmektedir (Mahaney ve Lederer, 2006). Ayrıca özgeci motivasyon ile hareket eden bireyler başkalarına gönüllü olarak yardım sağlamakta, başkaları için kaygı duymaktadır. Özgeci motivasyona sahip olan bireylerin öz sayg1, onur öz tatmin gibi değerleri üstü düzeydedir (Eisenberg ve Mussen, 1989). Bireylerin özgeci motivasyona sahip olması 
durumunda çok çaba sarfetme ve yapılacak işler için gönüllü olma, verimin artması için diğer öğretmenlere yardımcı olma ve onlarla sürekli iletişim kurma, onları cesaretlendirme ve sorun yaratabilecek işlerden uzak durma eğilimi gösterebileceği belirtilmektedir (Aycan, 2020). Sonuçlar incelendiğinde öğretmen adaylarının öğretmenlik programı seçiminde üç tema altında birleştiği söylenebilir. Dışsal sebeplerden dolayı öğretmenlik mesleğini tercih eden öğretmen adaylarının kendilerini meslek ile tam olarak özdeşleştiremediği, çıkar beklentileri ya da kendi dışında gerçekleşen bazı durumlar doğrultusunda mesleği seçtikleri gözlenmektedir (Bastick, 2000; Boz ve Boz, 2008). Bu durumun da zaman içerisinde öğretmenlik mesleğini bırakma noktasına getirdiği söylenmektedir (Erden, 2008). Bunun yanı sıra öğretmenlik mesleğini içsel ve özgeci sebeplerle seçen öğretmenlerin öğretmenlik motivasyonlarının daha yüksek olduğu ve verimli çalıştıkları söylenebilir (Sinclair, 2008). Bu durumda özgeci ve içsel motivasyonla sahip olan öğretmen adaylarının öğretmenlik mesleğine bakış açılarının, dışsal motivasyona sahip olan öğretmen adaylarına göre daha olumlu oldukları çıkarımı yapılabilir.

\section{Öneriler}

Okulun en önemli paydaşlarından biri olan öğretmenlerin adaylıktan itibaren öğretmenlik mesleği hakkındaki duygu-düşünceleri, beklentileri dikkate alınması gereken bir konudur. Ayrıca eğitim programının niteliğinin artırılması adına öğretmen adaylarının da deneyimlerinin belirlenmesi gerekir. Dolayısıyla bu konuda öğretmen adaylarının düşüncelerinin önemli olduğu düşünülmektedir.

Öğretmen adayları öğretmenlik mesleğini seçmeleri konusunda dışsal, özgeci ve içsel sebeplerin etkin olduğunu belirtmiştir. İçsel ve özgeci sebepler daha baskın olsa da dışsal sebepler de etkili olmaktadır. Dışsal sebepler incelendiğinde öğretmen adayları, öğretmenliği rahat çalışma ortamı olduğunu düşündükleri için seçmektedir. İçsel ve özgeci sebepler ile mesleğini seçen öğretmen adaylarının mesleklerinde daha başarılı olabilecekleri söylenebilir (Buldur ve Bursal 2015; Özkubat ve Demiriz, 2013). Bundan dolayı bireylerin lise döneminde kendi ilgi ve yeteneklerine uygun bir şekilde mesleğini seçmesi için onlara rehberlik edilmesi ve bu yönde meslek seçimleri için yönlendirilmesi önerilmektedir. Özellikle öğretmenlik mesleğinin dışsal sebeplerle seçilmesini önleyecek uygulamalar geliştirilmelidir ve özgeci ve içsel sebeplerle öğretmenlik mesleğini seçmeleri özendirilmelidir.

Öğretmen adayları öğretmenlik mesleğinden bazı beklentileri olduğunu belirtmiştir. Bunlar mesleki, sosyal ve ekonomik beklentilerdir. Öğretmenlerin mesleki gelişiminin sağlanması ve akademik beklentilerinin karşılanması ve mesleklerinde donanımlı bireyler haline gelmeleri için gerekli eğitimlerin sağlanması gerekmektedir. Bu bağlamda öğretmenlerin mesleki beklentilerini sağlamak için öğretmenlik meslek yeterlikleri bakımından (meslek gelişim, öğrenci tanıma, öğrenme-öğretme süreci, öğrenmeyi gelişimi izleme ve değerlendirme, okul aile ve toplum ilişkileri, program ve içerik bilgisi) eksik oldukları konuların belirlenip müfredatta gerekli ağırlıkların 
verilmesi önerilmektedir. Ayrıca sosyal ve ekonomik beklentiler arasında statü, saygı duyulma, maaş beklentisi gibi beklentiler bulunmaktadır. Öğretmenlik mesleğinin statüsünün geliştirilmesi için yasal, tüzüksel ya da yönetmeliksel olarak düzenlemelere gidilmesi önerilmektedir. Öğretmenlerin ekonomik beklentilerin karşılanması başarı odaklı maaş sistemi getirilebilir. Ya da sosyal statünün artırılabilmesi için yasal olarak öğretmenlerin çalışma şartları tekrar gözden geçirilebilir. Bu konularda yapılan düzenlemeler siyasi otoritenin öğretmenlere karşı bakış açısının ortaya koyulması, dolayısıyla sosyal statünün artması açısından önemlidir.

Öğretmen adayları öğretmen eğitim programının niteliğinin artırılabilmesi için öğretim yönteminin değiştirilmesi, öğretmenlik programını giriş şartlarının yeniden düzenlenmesi gibi önerilerde bulunmuştur. Özellikle öğretmenlik mesleğinin toplum için önemi dikkate alındığında politika yapıcıların bu önerileri ve diğer önerileri dikkate alıp gerekli tedbirleri alması önerilmektedir. Bu bağlamda hem öğretmen hem toplumun ihtiyacı doğrultusunda gerekli beceriler belirlenmeli ve öğretmenlere kazandırılması için çalışmalar yapılması önerilmektedir.

Öğretmen adaylarının büyük çoğunluğu ikinci bir tercih yapma şansları olması durumunda tekrar öğretmenlik mesleğinin seçeceklerini belirtmesine rağmen farklı meslekleri de seçebileceğini belirtenlerin sayısı oldukça fazladır. Bu durumda bu öğretmen adaylarının neden farklı bölüm seçebilecekleri konusunda düşüncelerinin araştırılması ve ortaya çıkarılması gerekmektedir. Bunun yanı sıra öğretmen adaylarına tercih sırasında kendi ilgi ve yeteneklerine uygun bölüm konusunda rehberlik edilmesi doğru mesleği tercih sırasında seçmelerine yardımcı olabilir. Özet olarak öğretmenlik mesleği için uygun adayların seçimini belirleyebilecek bir sistem kurulması önerilmektedir. Bu doğrultuda politika yapıcılara büyük iş düşmektedir.

Gelecek çalışmalarda bazı öğretmen adaylarının tekrar tercih yapmaları durumunda neden farklı bölüm seçmek istediklerinin belirlenmesi üzerine çalışılabilir. Bu konuda yapılacak nitel bir araştırma var olan durumun bir bütün olarak ortaya çıkmasını sağlayabilir. Öğretmenlerin mesleki öz yeterliklerinin veya iş performanslarının öğretmenlik mesleğini seçme motivasyonları bakımından (içsel, dışsal ve özgeci) farklılaşıp farklılaşmadığı nicel bir araştırma ile incelenebilir.

Etik Kurul İzin Bilgisi: Bu araştırma, Cumhuriyet Üniversitesi Bilimsel Araştırma ve Yayın Etiği Sosyal ve Beşeri Bilimler kurulunun 12/07/2021 tarihli E-60263016-050.06.04-57251 sayılı kararı ile alınan izinle yürütülmüş̧ür.

Yazar Çıkar Çatışması Bilgisi: Yazarın beyan edeceği bir çıkar çatışması bulunmamaktadır.

Yazar Katkısı: Makalenin hazırlanması ve düzenlenmesine ilişkin katkı ilgili yazar tarafindan gerçekleş̧irilmiştir. 


\section{Kaynakça}

Alkan, C. (2000). Meslek ve öğretmenlik mesleği. V.Sönmez (Ed.), Öğretmenlik mesleğine giriş (s.191-230) içinde. Ankara: Anı Yayınları.

Azman, N. (2013). Choosing teaching as a career: Perspectives of male and female Malaysian student teachers in training. European Journal of Teacher Education, 36(1), 113-130. doi: $10.1080 / 02619768.2012 .678483$

Aycan, M. M. (2020). Öğretmenlerde mesleki motivasyon ve örgütsel vatandaşllk davranışı arasındaki ilişsk (Yayımlanmamış yüksek lisans tezi). Pamukkale Üniversitesi, Eğitim Bilimleri Enstitüsü, Denizli.

Bergmark, U., Lundström, S., Manderstedt, L., \& Palo, A. (2018). Why become a teacher? Student teachers' perceptions of the teaching profession and motives for career choice. European Journal of Teacher Education, 41(3), 266-281. doi: 10.1080/02619768.2018.1448784

Balyer, A. ve K. Özcan. (2014). Choosing teaching profession as a career: Students' reasons. International Education Studies 7(5), 104-115. doi:10.5539/ies.v7n5p104.

Barnes, M. (2005). The Discriminatory effects of High-Stakes Testing in Georgia: Exploring causes and solutions. Education Law and Policy Forum, Education Law Consortium, The University ofGeorgia, Athens, GA.

Bastick, T. (2000). Why teacher trainees choose the teaching profession? Comparing trainees in metropolitan and developing countries. International Review of Education, 46(3/4), 343-349.

Beşoluk, Ş. ve Horzum, M. B. (2011). Öğretmen adaylarının meslek bilgisi, alan bilgisi dersleri ve öğretmen olma isteğine ilişkin görüşleri. Ankara Üniversitesi Eğitim Bilimleri Fakültesi Dergisi, 44(1), 17-49.

Boz, Y. ve Boz. N. (2008). Kimya ve matematik öğretmen adaylarının öğretmen olma nedenleri. Kastamonu Ĕ̈itim Dergisi, 16(1), 137-144.

Bozdoğan, A., Aydın, D. ve Yıldırım, K. (2007). Öğretmen adaylarının öğretmenlik mesleğine ilişsin tutumları. Ahi Evran Üniversitesi Kırşshir Eğitim Fakültesi Dergisi, 8(2), 83-97

Buldur, S. ve Bursal, M. (2015). The impact levels of career choice reasons of preservice science teachers and their future career expectations. Necatibey Eğitim Fakültesi Elektronik Fen ve Matematik Eğitimi Dergisi [Necatibey Faculty of Education Electronic Journal of Science \& Mathematics Education], 9(1), 81-107.

Bursal, M. ve Buldur, S. (2013). Fen bilgisi öğretmen adayları için öğretmenlik tercih nedenlerini derecelendirme ve geleceğe yönelik beklentiler ölçekleri geliştirme çalışması. Turkish Journal of Teacher Education, 2(1), 47-64.

Camelia, S., \& Elisabeta, P. M. (2013). Initial teacher training in Romania-a critical view. ProcediaSocial and Behavioral Sciences, 76, 780-784. doi: 10.1016/j.sbspro.2013.04.205 
Can, E. (2019). Öğretmenlerin meslekî gelişimleri: Engeller ve öneriler. Eğitimde Nitel Araştırmalar Dergisi - Journal of Qualitative Research In Education, 7(4), 1618-1650. doi: 10.14689/Issn.2148-2624.1.7c.4s.14m

Can, E. (2017). Öğrenci görüşlerine göre merkezî sınavların etkilerinin belirlenmesi. Akademik Sosyal Araştırmalar Dergisi, 5(58), 108-122

Can, Y. ve Soyer, F. (2008). Beden eğitimi öğretmenlerinin sosyo-ekonomik beklentileri ile iş tatmini arasındaki ilişki. Gazi University Journal of Gazi Educational Faculty (GUJGEF), 28(1), 61-74

Creswell, J. W. (2013). Qualitative, quantitative and mixed method approaches research design. (Çev. Ed. Demir, SB). Ankara: Eğiten Kitap

Çermik, H., Dogan, B. ve Sahin, A. (2010). Sınıf öğretmenliği öğretmen adaylarının öğretmenlik mesleğini tercih sebepleri. Pamukkale Üniversitesi Eğitim Fakültesi Dergisi, 28(2), 201-212.

Eisenberg, N. ve Mussen, P. H. (1989). The roots of prosocial behavior in children. Cambridge University Press.

Elma, C. ve Ergen, Y. (2016). Yeni mezun sınıf öğretmenlerinin sınıf öğretmeni yetiştirme programına ilişkin görüşleri. Kesit Akademi Dergisi, 2(4), 185-211.

Erden, M. (2008). Eğitim bilimlerine giriş. Ankara: Arkadaş Yayınevi.

Ergün, M. ve Avc1, S. (2012). Hollanda ve Türkiye'deki fen bilgisi öğretmeni yetiştirme programları hakkında öğretmen adaylarının görüşlerinin karşılaştırılması. Necatibey Eğitim Fakültesi Elektronik Fen ve Matematik Eğitimi Dergisi (EFMED), 6(1), 151-170.

Gömleksiz, M. N., Kan, A. Ü. ve Biçer, S. (2010). Öğretmen adaylarının öğretmenlik mesleğinden beklentileri (Frrat Üniversitesi örneği). Education Sciences, 5(2), 479-500.

Hacettepe Üniversitesi, Eğitim Fakültesi. (2017). Türkiye'de Öğretmen Eğitimi ve İstihdamı: Mevcut Durum Ve Öneriler. Erişim Adresi: http://fs.hacettepe.edu.tr/egitim/Raporlar/OgretmenEgitimi-istihdam_Raporu.pdf], Erişim tarihi: 2 Kasım 2021.

Haciömeroğlu, G. ve Taşkın, Ç. (2010). Fen bilgisi öğretmenliği ve ortaöğretim fen ve matematik alanları ofma eğitimi bölümü öğretmen adaylarının öğretmenlik mesleğine ilişkin tutumları. Ahi Evran Üniversitesi Kırşehir Eğitim Fakültesi Dergisi, 11(1), 77-90.

Hattie, J. (2009). Visible learning a synthesis of over 800 meta-analyses relating to achievement. London: Routledge.

İncikabı, L., Biber, A. Ç. ve Mercimek, O. (2016). İlköğretim matematik öğretmen adaylarının programı tercih nedenleri ve beklentileri üzerine bir araştırma. Adıyaman Üniversitesi Sosyal Bilimler Enstitüsü Dergisi, 8(22), 165-188. doi: /10.14520/adyusbd.67923

Jamil, H. (2014). Teacher is matter for education quality: A transformation of policy for enhancing the teaching profession in Malaysia. Journal of International Cooperation in Education, 16(2), 181-196. 
Karadağ, R. (2012). Türkçe öğretmeni adaylarının öğretmenlik mesleğine ilişkin tutumları ve öğretmenlik mesleğini tercih nedenleri. Humanities Sciences, 7(2), 44-66.

Koşar, D. (2018). Öğretmen adaylarının meslekten beklentilerine ilişkin görüşlerinin incelenmesi: Nitel bir araştırma. Journal of International Social Research, 11(56), 575, 585.

Kuzgun, Y. (2008). Meslek seçiminde bilinmesi gerekenler. Ankara: Ösym Yayınları

Low, E. L., Lim, S. K., Ch'ng, A., \& Goh, K. C. (2011). Pre-service teachers' reasons for choosing teaching as a career in Singapore. Asia Pacific Journal of Education, 31(2), 195-210. doi: $10.1080 / 02188791.2011 .567441$

Merriam, S. B., \& Grenier, R. S. (2019). Introduction to qualitative research. Qualitative research in practice: Examples for Discussion and Analysis. San Francisco: Jossey-Bass.

Moran, A., Kilpatrick, R., Abbot, L., Dallat, J., \& McClune, B. (2001). Training to teach: Motivating factors and implications for recruitment. Evaluation and Research in Education, 15(1), 1732. doi: $10.1080 / 09500790108666980$

Okçabol, R. (2004, Temmuz). Öğrenci, ögrretmen, ögrretmen adayı ve ögrretim elemanı gözüyle ögrretmen yetiştirme., XIII. Ulusal Eğitim Bilimleri Kurultayı, İnönü Üniversitesi, Eğitim Fakültesi, Malatya.

Öner, M. ve Yılmaz, R. K. (2019). Sınıf öğretmenliği eğitiminin niteliğinin artırılmasına yönelik öğretmen adayları ve öğretim elemanı görüşleri. Trakya Eğitim Dergisi, 9(4), 847-868. doi: $10.24315 /$ tred.533604

Özkılıç, R., Bilgin, A., ve Kartal, H. (2008). Öğretmenlik uygulaması dersinin öğretmen adaylarının görüşlerine göre değerlendirilmesi. İlköğretim Online, 7(3), 726-737.

Özkubat, S. ve Demiriz, S. (2013). Çevreye karşı motivasyon ölçeğinin okul öncesi öğretmen adayları üzerinde geçerlik güvenirlik çalışması. Amasya Üniversitesi Eğitim Fakültesi Dergisi, 2(1), 87-114.

Özsarı, İ. (2008). Eğitim fakültesi son sınıf öğrencilerinin KPSS merkezi sınavı odaklı gelecek kaygıları ve mesleki beklentileri (Yayımlanmamış yüksek lisans tezi). İstanbul Üniversitesi, Sosyal Bilimler Enstitüsü, İstanbul.

Papanastasiou, C., \& Papanastasiou, E. (1997). Factors that influence students to become teachers. Educational Research and Evaluation,3(4), 305-316. doi: $10.1080 / 1380361970030402$

Patton, M. Q. (2005). Qualitative research. New York: John Wiley \& Sons, Ltd

Sinclair, C. (2008). Initial and changing student teacher motivation and commitment to teaching. Asia-Pacific Journal of Teacher Education,36(2), 79-104. doi:10.1080/13598660801971658.

Şahin, İ. (2011). Öğretmen adaylarının öğretmen istihdamı ve mesleki geleceklerine ilişkin görüşleri. Kuram ve Uygulamada Eğitim Bilimleri, 11(3), 1167 - 1184. 
Şahin, Ç. ve Kartal, O. Y. (2013). Sınıf öğretmeni adaylarının sınıf öğretmeni yetiştirme programı hakkındaki görüşleri. Uşak Üniversitesi Sosyal Bilimler Dergisi, 6(1), 164-179.

Şahin, İ., Zoraloğlu, Y. R. ve Şahin-Fırat, N. Ş. (2011). Üniversite öğrencilerinin yaşam amaçları, eğitsel hedefleri üniversite öğreniminden beklentileri ve memnuniyet durumları. Kuram ve Uygulamada Ë̆itim Yönetimi, 3(3), 429-452.

Şahin, S., Uz Baş, A., Şahin Fırat, N. ve Sucuoğlu, H. (2012). İlköğretim okulu öğrenci ile öğretmenlerinin ortaöğretime geçiş sistemine ilişkin görüşleri. International Journal of Human Sciences, 9(2), 847-878.

Şara, P. ve Kocabaş, A. (2012). Sınıf öğretmeni adaylarının sınıf öğretmenliğini tercih nedenleri ve aldıkları eğitimle ilgili görüşleri. Turkish International Journal of Special Education and Guidance \& Counselling (TIJSEG), 1(2), 8-17.

Tataroğlu, B., Özgen, K. ve Alkan, H.(2011). Matematik öğretmen adaylarının öğretmenliği tercih nedenleri ve beklentileri. 2nd International Conference on New Trends in Education and Their Implications. Ankara: Siyasal Kitabevi.

Thomson, M. M., Turner, E. J., \& Nietfeld, J. L. (2012). A typological approach to investigate the teaching career decision: Motivations and beliefs about teaching of prospective teacher candidates. Teaching and Teacher Education 28(3), 324-335. doi:10.1016/j.tate.2011.10.007.

Tunca, N., Alkın-Şahin, S., Oğuz, A. ve Bahar-Güner, H. O. (2015). Qualities of ideal teacher educators. Turkish Online Journal of Qualitative Inquiry, 6(2),123-148. doi: 10.17569/tojqi.48192

Uras, M. ve Kunt, M. (2006). Öğretmen adaylarının öğretmenlik mesleğinden beklentileri ve beklentilerinin karşılanmasını umma düzeyleri. Pamukkale Üniversitesi Eğitim Fakültesi Dergisi, 19(1), 71-83.

Üstüner, M. (2006). Öğretmenlik mesleğine yönelik tutum ölçeğinin geçerlik ve güvenirlik çalışması. Kuram ve Uygulamada Ĕ̈itim Yönetimi, 12(45), 109-127.

Watt, H. M., \& Richardson, P. W. (2008). Motivations, perceptions, and aspirations concerning teaching as a career for different types of beginning teachers. Learning and Instruction, 18(5), 408-428.

Yeşilyurt, E. ve Karakuş, M. (2011). The problems teachers encountered during the candidacy process. International Online Journal of Educational Sciences, 3(1), 261-293.

Yıldırım, A. (1999). Nitel araştırma yöntemlerinin temel özellikleri ve eğitim araştırmalarındaki yeri ve önemi. Eğitim ve Bilim, 23(112), 7-17.

Yıldırım, A. ve Şimşek, H. (2013). Sosyal bilimlerde nitel araştırma yöntemleri. Ankara: Seçkin Yayıncilik.

Yıldırım, N. ve Öner, S. (2016). Etkili/başarılı sınıf öğretmenleri üzerine nitel bir analiz. Ahi Evran Üniversitesi Kırşehir Eğitim Fakültesi Dergisi, 17(3), 135-155. 
Reasons for Choosing the Teaching Profession for Teacher Candidates, Their

Expectations, and Opinions About Increasing the Quality of the Teaching Program

\author{
Mehmet Yaşar KILIÇ*
}

- Received: 02.12.2021 • Accepted: 21.02.2022 • Online First: 21.02.2022

\begin{abstract}
This study aims to determine the reasons for choosing the teaching profession of teacher candidates, their expectations from the teaching profession, and their views on increasing the quality of the teaching program. The research was carried out by the case study, one of the qualitative analysis methods. The research participants are 23 teacher candidates studying at the education faculty in the 2020-2021 academic year. Participants were determined by the convenience sampling method, one of the purposeful sampling methods. The researcher created a semi-structured interview form as a data collection tool in the study. "Content analysis" was performed on the collected data with the NVivo 10 qualitative analysis program. "Content analysis" was performed on the collected data with the NVivo 10 qualitative analysis program. As a result of the research, it was seen that the reasons for choosing the teaching profession of teacher candidates were grouped under three sub-themes external reasons, altruistic reasons, and internal reasons. In addition, it was concluded that the expectations of teacher candidates from the teaching profession were gathered under three subthemes: professional expectations, social expectations, and economic expectations. When the views of the teacher candidates on increasing the quality of the teaching program were evaluated, it was found that there should be more applied courses, the entrance conditions should be regulated, the number of students should be reduced, experienced instructors, effective communication, adequate support, and physical facilities categories were obtained. Additionally, most teacher candidates stated that they would choose the teaching profession again if they had a chance to make a second choice. Some teacher candidates say that they will choose different professions.
\end{abstract}

Keywords: teacher candidates, teacher expectations, teacher qualifications, the teaching profession, teaching program

\title{
Cited:
}

Kılıç, M.Y. (2022). Reasons for choosing the teaching profession for teacher candidates, their expectations, and opinions about increasing the quality of the teaching program. Pamukkale University Journal of Education, 56, 35-65.doi: 10.9779.pauefd.1031456

\footnotetext{
* Asst. Prof. Dr., Cyprus Science University, ORCID: 0000-0002-8675-5126, myasarkilic@csu.edu.tr
} 


\section{Introduction}

Today, changes and developments in technological, economic, social, and cultural fields affect many education systems. As a result, it brings many changes. The education system has a vital role in raising individuals with the necessary knowledge and skills for the development of countries and in ensuring their technological, economic, social, and cultural continuity. The quality of the education system depends on qualified teachers who can effectively fulfill the system's requirements (Karadağ, 2012). Teaching is a strategic profession that shapes the way of life of individuals and society and shapes the future of organizations (Alkan, 2000). The productivity of teachers, who are the cornerstones of the education system, directly affects the quality of education (Ergün \& Avc1, 2012). Therefore, teacher candidates who will raise future generations should be trained competently. For this reason, this study was conducted to determine the motives of teacher candidates for choosing the teaching profession, their expectations, and their views on increasing the quality of the teaching program.

\section{Choosing a Profession and Factors Affecting Choosing a Profession}

To increase the qualifications that teacher candidates should have, the reasons for choosing the profession of teacher candidates and their expectations from the profession play a decisive role (Hacıömeroğlu \& Taşkın, 2010; Tataroğlu, Özgen \& Alkan, 2011). To be a qualified teacher, an individual should choose his profession consciously love his profession. There should be harmony between his characteristics and the features required by the teaching profession (Şara \& Kocabaş, 2012). Suppose individuals do not choose a profession that suits their wishes and abilities. In that case, they will likely be negatively affected by the situation and experience professional dissatisfaction (Kuzgun, 2008). This is can be valid for the teaching profession, as it is for many professions.

Studies show that the individual's internal, external and altruistic motives come to the fore in choosing the teaching profession (Balyer and Özcan 2014; Moran, Kilpatrick, Abbot, Dallat, \& McClune, 2001; Thomson, Turner, and Nietfeld 2012). Intrinsic motivations are the natural aspects associated with the individual's willingness to show, the meaning of teaching for himself, his knowledge and expertise on the topic. Extrinsic motives include factors such as an individual's status, salary, vacations, and working conditions. Altruistic reasons include the perception of teaching as a valuable profession the individual's desire to create a difference in teaching and contribute to children's development. It is stated that the countries with intrinsic and altruistic motives are developed countries, while the countries with extrinsic reasons are developing countries (Azman 2013; Low, Lim, Ch'ng, \& Goh, 2011). Papanastasiou and Papanastasiou (1997) studied teacher candidates within the U.S.A. and Cyprus. As a result of the research, it was concluded that choosing teacher candidates in the U.S.A. depends on intrinsic motivation, and in Cyprus, on 
extrinsic motivation. In the study conducted by Boz and Boz (2008), external factors were determined as the most significant determinant of the reasons for chemistry and mathematics teacher candidates to choose the teaching profession. Intrinsic and altruistic motives follow this. In addition, the research results show that the motivations of the individual towards the teaching profession should consist of a mixture of these three concepts so that they can be permanent in the teaching profession (Sinclair, 2008).

\section{Teacher Expectations and Qualifications}

Teacher candidates may have chosen their profession with a confident expectation by evaluating many situations that will provide to the teaching profession itself. In other words, they have expectations about the teaching profession in the candidate period (Gömleksiz, Kan, \& Biçer, 2010). With the selection of the profession, expectations about the profession are formed (Uras \& Kunt, 2006). If the professional expectations of individuals are not met, there will be no job satisfaction. As a result, individuals develop negative attitudes towards their work environment and managers (Can \& Soyer, 2008). Meeting the expectations of individuals has positive effects on their morale, motivation, and job satisfaction. It is stated that motivated and satisfied individuals make more effort at work and are more likely to succeed (Uras \& Kunt, 2006). It is thought that the quality of the teaching program should be increased at the desired level to meet the expectations of teacher candidates.

Teacher education includes policies, practices, programs, and multidimensional teaching processes designed to equip prospective teachers with the knowledge, skills, attitudes, and behaviors needed to perform their duties efficiently in the classroom, school, or different environments. Teacher education reflects the value of preparing individuals who grew up in that country for the future. For this reason, various practices can be seen in the education policies of each government. Therefore, the process of increasing the quality of teacher education is a controversial issue today (Öner \& Y1lmaz, 2019). The world's most successful education systems have consistently focused on improving the quality of teachers. Especially in education policies, practices aimed at raising the education standard and increasing the quality of teachers are frequently observed (Jamil, 2014). In addition, how the teacher candidate are selected, the characteristics of the teacher candidate who are accepted into the program, the training they receive before the service, the qualifications of the lecturers, and the teaching-teaching environment also directly or indirectly affect the capabilities of the teachers (Tunca, Alkın-Şahin, Oğuz \& Bahar-Güner, 2015). When the studies are examined, it can be said that the quality of teachers has essential effects on student achievement. In the study conducted by Hattie (2009), it was concluded that the quality of teachers is a crucial determinant of students' school success. Similarly, Camelia and Elisabeta (2013) state that the education received by teachers in the candidate period positively affects student achievement. 
Within the scope of this study, teacher candidates were also asked about the professions they would prefer if they had the chance to make a second choice. This question was asked to obtain information about their satisfaction with their chosen profession rather than their willingness to choose. Therefore, this situation is related to whether the teacher candidates like their profession or not. As a result of their study, Y1ldirım and Öner (2016) concluded that teachers should love their profession to be effective and successful teachers. Therefore, teachers' love of their profession is essential for success.

There are constant changes in teacher training practices and working conditions of the teaching profession. For this reason, it is essential to determine the attitudes of teacher candidates studying in teacher training programs towards their profession and to conduct current studies (Üstüner, 2006). In order to ensure the continuity of the education system, in faculties of education that train teachers, it is necessary to determine the reasons for choosing the profession and their expectations from the profession to increase the qualifications of teacher candidates and take action in this direction. An in-depth examination of teacher candidates' thoughts and expectations on this subject can provide helpful information to faculty members and policymakers to increase the proficiency of teacher candidates. Şahin (2011) states that to establish and shape the future of society on healthy foundations, teachers should be trained well-equipped in every aspect. To achieve this, prospective teachers' hopes for the future should be kept alive. From this point of view, determining the professional expectations of teacher candidates who will raise future generations is essential for the steps taken towards the development of education. In addition, it is thought that determining the views of teacher candidates on increasing the quality of the teaching program may contribute to the structuring of the teacher training process in line with current expectations. It is hoped that the results to be obtained will be a resource for realizing the teacher training process more efficiently and effectively, increasing the quality of the teaching programs, and for the plans to be made in this direction. In addition, it is thought that the results to be obtained are essential in terms of providing up-to-date information and creating resources for researchers and practitioners.

This study aims to determine the reasons for choosing the teaching profession, their expectations from the teaching profession, and their views on increasing the quality of the teaching program.

For this purpose, answers to the following questions are sought;

1. What are the opinions of prospective teachers about the factors that are effective in choosing the teaching profession?

2. What are prospective teachers' views on the factors that determine their expectations from the teaching profession? 
3. What are the opinions of teacher candidates about what can be done to increase the quality of teacher education programs?

4. What professions could teacher candidates choose if they had a chance to make a second choice?

The main purpose of determining teacher candidates' views on the factors that affect their choice of the teaching profession is to reveal which motivational factors influence the teaching profession. The main purpose of determining teacher candidates' views on the factors that determine their expectations from the teaching profession is to reveal the expectations of teacher candidates in choosing the profession. The main purpose of taking teacher candidates' opinions on what can be done to increase the quality of the teaching program is to reveal the teachers' thoughts on this subject. The main purpose of the question, "What are the professions they could choose if they had a chance to make a second choice?" is related to the motivation of the prospective teachers towards the teaching profession. It is expected that teachers who choose their profession in line with intrinsic and altruistic reasons do not want to change their profession. In contrast, teachers who desire extrinsic motivation are expected to choose a different profession.

\section{Method}

In this part of the research, the model, the participants, the data collection tool, and the data analysis are presented in order.

\section{Methodology}

The research was carried out by the case study, one of the qualitative research designs. Qualitative research aims to reveal the observation results holistically, without distorting them, by observing the phenomena desired to be kept in their natural environment (Y1ldırım, 1999). On the other hand, case studies examine a specific situation in depth. In this way, the factors that reveal the problem are reviewed holistically, and the result is reached (Yıldırım \& Şimşek, 2013). Case studies focus on an identified event or situation. Then, the findings are examined intensively, and the situation or circumstance is explained (Merriam \& Grenier, 2019). In this study, the case study was used to explore the research questions and reveal the participant's views.

\section{Participants}

The research participants consisted of 23 teacher candidates studying at the education faculty in the 2020-2021 academic year. Teacher candidates are educated in classroom teaching, Turkish education, and mathematics education. When the data collected from the participants start to repeat itself, the data collection process is terminated (Creswell, 2013). In this direction, when the data started to repeat, the data collection process was terminated. Participants were determined by the convenience sampling method, one of the purposeful sampling methods. In this sampling method, participants who are easier and faster to reach are included in the research (Patton, 2005). 52.2\% of 
the research participants were male $(n=12)$ and $47.8 \%$ were female $(n=11)$. In addition, $26.1 \%$ of the participants were in the 1 st grade $(n=6), 21.7 \%$ were in the 2 nd grade $(n=5), 26.1 \%$ were in the 3 rd grade ( $n=6)$ and $26.1 \%$ were in the 4 th grade $(n=6)$ is studying.

\section{Data Collection Tools}

The researcher created a semi-structured interview form as a data collection tool in the study. The semi-structured interview form consists of four questions. To evaluate the suitability of the questions designed for the purpose and language rules, the opinions of 3 experts were consulted (two from educational sciences and one from linguistics). Thanks to the feedback received from the experts, the semi-structured interview form was finalized. Thus, it was aimed to ensure the internal validity of the study (Yıldırım \& Şimşek, 2013). A pilot study was conducted with two participants to determine whether the semi-structured interview form prepared by the researcher serves to resolve the problems that may arise before the application and fix the unpredictable negative situations. The answers given as a result of the application were evaluated, and the actual application was started.

\section{Data Collection and Analysis}

Data were collected between May 15 and June 10, 2021. In the semi-structured interview form prepared, information about the importance and scope of the research and how to fill the interview form was given. In the study, data were collected in line with the principle of voluntariness. The collected data was first transferred to the computer as a Word document, and "content analysis" was performed with the NVivo 10 qualitative analysis program. The main purpose of content analysis is to bring together similar expressions in line with certain concepts and themes and to interpret these concepts and themes in a way that the reader can understand (Yıldırım \& Şimşek, 2013). As a result of the content analysis, a separate table was created for each research question. The sample expressions regarding the categories and sub-categories were listed with the coding system. For example, P1 coding represents the first participant. Participants expressed more than one opinion on the categories or sub-categories.

It is stated that in qualitative research methods, validity can be ensured with expert opinion and participant confirmation, and reliability can be ensured with confirmation examination (Yıldirım \& Şimşek, 2013). In this context, after the data collected from the participants were transferred to the Word environment, the participants were reached again, they were asked to read the statements, and their confirmations were obtained. As a result, it aimed to increase the study's validity. To ensure the reliability of the study, the data were examined separately by a person from the field of educational sciences and the researcher, and themes, categories, and sub-categories were created. Then, the consistency of the themes, categories, and sub-categories obtained was compared. The themes received, the motivation of prospective teachers to choose the teaching profession, were determined as the factors determining the expectations of teacher candidates from the teaching profession. In 
addition, sub-categories were obtained to increase the quality of teacher education programs. Finally, the professions that teacher candidates could prefer if they had the chance to make a second choice were examined.

\section{Findings}

In this section, the data collected from the participants are examined in line with the research questions.

\section{1- Analysis of the Reasons of Teacher Candidates for Choosing the Teaching Profession}

Table 1 was formed due to the analysis of the participants' opinions on the reasons for choosing the teaching profession. In addition, the participant's views on the reasons for choosing the teaching profession were directly quoted and exemplified under the relevant category.

Table 1. Themes and Categories Regarding the Reasons of Teacher Candidates for Choosing the Teaching Profession

\begin{tabular}{lllc}
\hline \multicolumn{1}{c}{ Main Theme } & \multicolumn{1}{c}{ Subtheme } & Categories & Frequency \\
\hline & \multirow{4}{*}{ External Reasons } & Comfortable Working Environment & 16 \\
& & More Holidays & 12 \\
& & Regular Income & 10 \\
& & A Respectable Profession & 8 \\
& & Job Guarantee & 7 \\
Teacher & Entry Score & 5 \\
Candidates' & Recommendation & 3 \\
Motivation for & Altruistic Reasons & Serving Humanity & 15 \\
Choosing a & Being a Role Model & 11 \\
Profession & Touching People's Lives & 11 \\
\cline { 2 - 4 } & & Lifelong Learning & 10 \\
& & Like to Teach & 9 \\
& & Like to Communicate & 6 \\
& & Ideal Job for Me & 5 \\
& & Teachers Being Role Models & 5 \\
& & Loving the Children & 4 \\
& & Loving the School Environment & 2 \\
\hline
\end{tabular}

As discussed in Table 1, the main theme of teacher candidates' motivation to choose a profession and sub-themes of external reasons, altruistic reasons, and internal reasons were obtained. 
The main theme, sub-themes, and the expressions of the categories related to these sub-themes are given below.

External reasons: Some teacher candidates in the study group associate the reasons for choosing to teach with external ones. The participants' opinions regarding the categories included in this subtheme are exemplified below.

- Comfortable working environment: It has been determined that the most attribution regarding the reasons for choosing the teaching profession of teacher candidates is made in the "comfortable working environment" category. In other words, teacher candidates prefer the teaching profession because of the comfortable working environment. Some opinions regarding this category are exemplified below.

"...compared to many other professions, it is an important factor that the working environment in the school is comfortable and clean. In addition, the people I will work with at the school will be people with a certain level of education. Therefore, there will be a comfortable environment in which it will be comfortable to communicate... (P2)."

"...the school environment is comfortable for working. We must work on what we will do for the students in this comfortable environment ...(P7)."

"...teaching in a comfortable environment was the reason for my preference. This allows teachers to focus only on their work... (P15)."

- More holidays: One of the categories with the highest number of references by teacher candidates is in the category of "more holidays." Teacher candidates prefer the teaching profession because it has more holidays. Some of the comments referenced in this category are presented below.

"...the teaching profession has more holidays than other professions. I can take a longer vacation in the summer. I can devote more time to myself. This situation makes teaching more attractive than other professions... One of the factors in my choice of the teaching profession is that it takes a lot of vacations... (P3)."

"...the profession that takes the most vacations is teaching. Because of this, I can earn money without getting too tired. I can also take care of my family more... (P11)"

- Regular income: Katılımcıların görüşleri doğrultusunda elde edilen diğer bir kategori ise "düzenli gelir" kategorisidir. In other words, the participants choose the teaching profession to have a regular income. The participant opinion that can reference this category is as follows.

“... my salary is regularly, I can plan my future according to my salary. This is one of the reasons why the profession is attractive and why I prefer it. (P13)"

- A respectable profession: Another category expressed by an essential part of the participant group is "a respectable profession." In other words, teacher candidates prefer the teaching profession because it is a respectable profession. The related category was "...teaching is a profession respected by the society. After all, teachers have a say in the future of the country... (P5)" represents the view. 
- Job guarantee: Another category obtained in line with participant opinions is "job guarantee." In other words, teacher candidates choose the teaching profession because it is a job guarantee. Regarding this category, "... a guaranteed profession after being appointed as a teacher. It's a job that I can always work in. I can work until I retire... (P17)" can be given as an example.

- Entry score: Another category obtained from the qualitative analysis is the "entry score" category. Some teacher candidates state that they chose this profession because their exam scores were sufficient for the teaching entrance score. Some of the opinions that can reference this category are exemplified below.

"My score was only enough for the teaching program. That's why I chose the teaching profession. If I had a high score, I would probably prefer another department (P18)."

"I chose the teaching profession because I had enough points. There is no particular reason for me. (P19)"

- Recommendation: At the point of choosing the teaching profession, the "advice" category was obtained in line with the opinion of a person. Teacher candidates state that they chose the teaching profession due to the recommendation. This category includes "...many of my acquaintances and relatives in my close circle are teachers. When I talked to them, they said that teaching was the most suitable profession for me. They told me about the positive aspects of the teaching profession for years. They have engraved the teaching profession in my mind since I was little... (P23)" explains the statement.

Altruistic reasons: Some of the teacher candidates in the study group associate the reasons for choosing teaching with altruistic reasons. The participants' opinions regarding the categories included in this sub-theme are exemplified below.

Serving humanity: When the teacher candidates' views are examined, it is seen that the most attribution is made to the category of "serving humanity." In other words, it can be said that teacher candidates prefer the teaching profession to serve humanity. Some of the opinions that may reference this category are exemplified below.

"...the upbringing of students is a significant issue. The teachers, scientists, and administrators of the future will emerge from the students we train. These people will have important contributions to the development of humanity... (P16)."

"...if I become a teacher, I dream of improving myself throughout my life and educating students in the best way possible. In other words, my most important dream is to raise wellequipped individuals. I chose the teaching profession to contribute to education and bring it to better levels... (P9)."

Being a role model: According to the teacher candidates' opinions, the category of "being a role model" was obtained regarding the reasons for choosing the teaching profession. In other words, teacher candidates prefer the teaching profession to be a role model for students and their environment. Two of the opinions that can reference this category are given below. 
"...I chose this profession because of my teachers being a role model for me. I also want to be a role model for my students and those around me. To raise the prestige of the teaching profession, I need to behave in a way that suits the profession ...(P4)."

"...in my environment, teachers are shown as role models. If everyone wants to get an opinion on a subject, the teacher asks the person they know. Therefore, everyone's perspective on teachers is different. That's why I chose to teach (P1)."

- Touching people's lives: One of the categories in which the participants expressed opinions is "touching people's lives." Teacher candidates prefer the teaching profession to touch the lives of students. Views that can be references to this category are exemplified below.

"...I chose the teaching profession to leave a mark in the lives of students who will become teachers, doctors, and engineers in the future, and to contribute to their upbringing... (P16)."

"...I think it is an excellent feeling to be with people, to help them, to take care of them for a part of their life... (P10)."

Internal reasons: Some teacher candidates in the study group associate the reasons for choosing teaching with internal reasons. The participants' opinions regarding the categories included in this sub-theme are exemplified below.

- Lifelong learning: As a result of the content analysis, it has been determined that one of the most cited categories is "lifelong learning." The participants chose the teaching profession in this context because of the lifelong learning factor. Two of the opinions that refer to this category are exemplified below.

"...I don't want to lag behind the times, so I need to improve myself and learn new things.

That's why I thought the teaching profession might be just right for me. I need to prepare myself and my students well for the future... (P14)."

"Sürekli gelişim odaklı bir kişiliğe sahibim. Yeniliği ve yeni şeyleri seviyorum. Öğretim ayrıca sürekli araştırma ve geliştirmeyi içerir. Bana uygun bir iş...(K9)"

- Like to Teach: Another category obtained by the participants among the reasons for choosing the teaching profession is the category of "like to teach." Teacher candidates prefer the teaching profession because they like to teach. Some of the opinions referring to this category are as follows.

"I love to teach what I have learned to those around me. While doing the teaching work, I concentrate on my own, and I am happy at the end. Learning things and teaching them is an ideal situation for me... (P5)."

"...I am constantly reading and learning. I don't think it will do anyone any good to keep what I've learned to myself. It gives me happiness to teach other people and students what I teach... (P17)."

- Like to Communicate: In line with the opinions of a significant part of the participants, the category of "like to communicate" was obtained. In other words, teacher candidates prefer the 
teaching profession because they like to communicate. This category includes "...I like communicating with people. I think my communication side is strong. The teaching profession also requires constant communication. Therefore, I think that I can be successful in the teaching profession (P5)".

- Ideal Job for Me: One of the categories obtained in line with the participants' statements is "Ideal Job for Me." I have always wanted to be a teacher since I was a child. I don't know exactly what impressed me, but teaching has always been my ideal profession... (P6)" exemplifies the view.

Teachers Being Role Models: According to the teacher candidates' opinions, the category of "teachers being role models " was obtained. Teacher candidates state that their teachers' role as an example is influential in their teacher selection. This category is "...I have had many teachers throughout my education life. Among these teachers, I had teachers who supported my behavior and communication style and made me love this profession. Thanks to them, I thought that being a teacher would be more suitable for me (P4)" exemplifies.

- Loving the Children: Another category obtained from the data analysis is "loving the children." In this category, "...taking care of children has always been a fun job for me. While taking care of children, I can officially be a child. I get down to their level and think the way they think. I like to take care of them... (P10)" can be given as an example.

- Loving the School Environment: The last category for teachers' motivation to choose a profession is "liking the school environment." In other words, teacher candidates prefer the teaching profession because they like the school environment. The opinions expressed for this category are "...the learning environment at school is an environment we have been through for years. This environment gives me peace. I feel more productive in the school environment. I think I can be more useful in this environment... (P14)" can be given as an example.

\section{2- Analysis of the Expectations of Teacher Candidates from the Teaching Profession}

The main theme and three sub-themes were created regarding the expectations of teacher candidates from the teaching profession. The sub-themes were professional expectations, social expectations, and economic expectations. As seen in Table 2, most references were made to the professional expectations sub-theme, secondly to the social expectations sub-theme, and finally to the economic expectations sub-theme. In addition, categories related to sub-themes were created.

Table 2. Themes and Categories Related to Expectations from the Teaching Profession

\begin{tabular}{|c|c|c|c|}
\hline Main Theme & Subtheme & Categories & Frequency \\
\hline \multirow{5}{*}{$\begin{array}{l}\text { Future } \\
\text { Expectation } \\
\text { from the } \\
\text { Profession }\end{array}$} & \multirow{5}{*}{ Professional Expectations } & Professional Development & 17 \\
\hline & & Working Environment & 17 \\
\hline & & Academic Progress & 14 \\
\hline & & Raising Equipped Youth & 9 \\
\hline & & Loving the Profession & 8 \\
\hline
\end{tabular}




\begin{tabular}{llc}
\hline \multirow{2}{*}{ Social Expectations } & Shaping the Future & 12 \\
& Social Status & 10 \\
& Healthy Communication & 6 \\
\hline \multirow{2}{*}{ Economic Expectations } & Salary Expectation & 6 \\
& Additional Discounts & 3 \\
\hline
\end{tabular}

As seen in Table 2, the main theme of future expectations from the profession and subthemes of professional expectations, social expectations, and economic expectations were obtained. The main theme, sub-themes, and the expressions of the categories related to these sub-themes are given below.

Professional expectations: It is concluded that the majority of the teacher candidates in the study group have professional expectations from the teaching profession. Some of the opinions expressed regarding the categories in this sub-theme are exemplified below.

- Professional development: It has been determined that the most attribution regarding the expectations of teacher candidates from the teaching profession is made in the "professional development" category. Teacher candidates expect to develop themselves professionally in the teaching profession. Some of the participants' opinions regarding this category are presented below.

"After being appointed to the teaching profession, I want to improve myself in my field and become a competent teacher. At the top of my expectations is the provision of my development... (P9)."

"...I need to master the subjects I will teach the students. Therefore, it is at the forefront of my expectations to learn these subjects in-depth and improve myself. Starting from the first years of my profession, I will constantly work to improve myself... (P14)."

"I need to educate myself in my field so that I can be useful to students and ensure their full development. In addition, I have to renew myself in the changing world constantly. It is important to acquire new knowledge as knowledge is constantly changing... (P7)."

- Working environment: The second most uploaded category by the participants is the "working environment" category. Participants have expectations for the working environment in schools. Participant opinions that can be references to this category are as follows.

"I expect the working environment at school to be peaceful. A positive school environment that will meet the expectations of teachers will benefit teachers and students... (P14)."

"The environment in which I work needs to have a supportive climate. Working in an environment where everyone helps each other ensures a more productive education. I want to work in a school with a productive environment ... (P6)."

- Academic progress: It was concluded that a significant part of the teacher candidates referred to the category of "academic progress." Teacher candidates have expectations for academic advancement in 
teaching. I want to advance academically after I become a teacher. I want to take part in school administration. I want to experience the principal school experience... (P17)" represents the view.

- Raising equipped youth: In line with the opinions expressed by the participants, the category of "raising well-equipped students" was obtained. This category is defined as "...students need to graduate well-equipped while graduating. To achieve this, the necessary acquisitions must be given to the students. My greatest expectation is that they graduate with the necessary skills... (P10)" exemplifies the opinion.

- Loving the profession: The other category obtained from the content analysis is "loving the profession." An example of this category is the view "...I did not choose the profession voluntarily; therefore I want to love the profession in the future and fulfill its requirements in the best way... (P23)".

Social expectations: It was concluded that some teacher candidates have social expectations from the teaching profession. Some statements regarding the categories in this sub-theme are exemplified below.

Shaping the future: In line with the teacher candidates' opinions, the category of "shaping the future" was obtained. In this case, it can be said that teacher candidates are in anticipation of shaping the future. Some of the opinions that can reference this category are as follows.

"...I think it would be nice to take part in raising young people who will have a say in the future of the country and increasing their qualifications. My biggest expectation is to contribute to the upbringing of young people... (P15)."

"Meeting the expectations of students and the society coincides with my expectations... (P13)."

- Social status: As a result of the analysis, the "social status" category was obtained. Teacher candidates expect the teaching profession to give them social status. Some of the opinions that can reference this category are given below.

"...I think that teaching is a respectable profession. I imagine that in the future when I enter society, I can be shown as a respected personality...(P10)."

"Teaching has more responsibilities than any other profession. This is due to the impact of the teaching profession on the whole society. I think that teaching will add value to my social life... (P14)."

- Healthy communication: One of the categories obtained as a result of content analysis is "healthy communication." In this category, "...one of my expectations is to have an environment where I can communicate healthily, especially in the school environment. The view that everyone can express themselves freely and freely resolves conflicts... (P16)" can be given as an example.

Economic expectations: Few research participants state that they have financial expectations from the teaching profession. Sample expressions related to the categories created in line with this subtheme are exemplified below. 
- Salary expectation: As a result of the statements of the teacher candidates, the "salary expectation" category was obtained. Their opinions regarding the related category were "...I need to receive a regular salary so that both myself and my family can lead a comfortable life. The teaching profession can be a tool for me to receive a regular salary... (P23)".

- Additional discounts: One of the expectations of teacher candidates from the teaching profession is "additional discounts." This category was defined as "...I expect additional incentive discounts for teachers. In particular, providing additional discounts on many products such as books and computers can motivate teachers more... (P22)" exemplifies the opinion.

\section{3- Analysis of Teacher Candidates' Opinions on Increasing the Quality of Teacher Education Programs}

Table 3 was created as a result of the opinions of the research participants on increasing the quality of teacher education programs. In Table 3, the categories and sub-categories created in line with teacher candidates' views on improving the quality of teacher education programs are given.

Table 3. Categories and Sub-Categories for Increasing the Quality of Teacher Education Programs

\begin{tabular}{ccc}
\hline Category & Sub-category & Frequency \\
\hline & Teaching Method Should Be Changed & 16 \\
& Entry Conditions Should Be Regulated & 12 \\
Increasing the Quality & The Number of Students Should Be Reduced & 9 \\
of Teacher Education & Experienced Instructor & 7 \\
Programs & Effective Communication & 6 \\
& Sufficient Support & 4 \\
\hline
\end{tabular}

As seen in Table 3, sub-categories of "teaching method should be changed," "entry conditions should be regulated," "the number of students should be reduced," "experienced instructor," "effective communication," "sufficient support," and "physical facilities" were obtained.

The teaching method should be changed: It was concluded that among the sub-categories related to increasing the quality of teacher education programs, the most attribution was made to the "teaching method should be changed" sub-category. Participants think that the teaching method should be changed to increase the quality of teacher education programs. Some of the opinions that can be references to this sub-category are given below.

"The majority of the courses are theoretical. I think that teacher candidates can gain more experience and increase their qualifications by applying it practically...(P3)."

"...by increasing the number of applied courses, we can at least learn by doing. This helps to train teachers who are fit for purpose...(P7)."

"Some teachers explain some teaching methods and techniques in the lesson, but frankly, it doesn't make any sense if you can't learn those techniques by experience. When we are 
appointed to the profession, we need to gain experience at the university so that we can work more efficiently... (P12)."

Entry conditions should be regulated: In line with the opinions obtained on increasing the quality of teacher education programs, the sub-category of "entry conditions should be regulated" was obtained. The comments below exemplify this sub-category.

"I don't see teaching as a profession that everyone can do. To be a teacher, the personality traits of an individual are essential. Making a multi-stage entry system for entry to teaching increases the quality...(P10)."

"Teaching is a special profession. You must meet certain criteria. Your communication skills must be strong. You need to express yourself well. You have to be patient. A new evaluation system should be introduced by taking these criteria into account in selecting teachers... (P16)."

The number of students should be reduced: As a result of the data collected to increase the quality of teacher education programs, the category of "the number of students should be reduced" was obtained. In this category, "more efficient and effective education can be realized by reducing the number of students. In this way, teachers can deal with students one-on-one and follow their development (P15)" as an example.

Experienced instructor: In line with the opinions of some of the teacher candidates participating in the research, the category of "experienced instructor" was obtained. Participants state that the quality of teacher training programs can be increased by training experienced instructors. The view that can be a reference for this category is "...the quality can be increased by giving lectures by more experienced instructors. To train inexperienced instructors, it can be ensured that they take part in less important courses... (P17)".

Effective communication: Some teacher candidates state that effective communication can increase the quality of teacher education programs. Regarding this category, "the level of communication between university professors and students increases the quality. Some teachers teach their lessons and leave, while the rest act as if they don't care. Teachers need to communicate effectively... (P5)" can be given as an example.

Adequate support: In line with the opinions of the research participants, it is stated that the quality of teacher education programs can be increased if adequate support is provided to teacher candidates. One of the participants said, "Material and moral support should be provided to teacher candidates. Support and incentives provided by the government can improve the quality of education. Students may have difficulties that they cannot overcome on their own. Providing support for the solution of these increases the motivation of teacher candidates...(P6)".

Physical facilities: Another category obtained in line with the statements of teacher candidates in the category of "physical facilities." Teacher candidates state that physical facilities should be provided to increase the quality of teacher education programs. Regarding this category, "teacher candidates 
must have sufficient physical means. Concrete opportunities should be provided for all methods and techniques used in education. In addition, providing social opportunities helps the teacher candidates to develop himself as a whole...(P13)" can be given as an example.

\section{4- Analysis of Teacher Candidates' Opinions About the Profession They Would Choose If They} Had a Chance to Make a Second Choice

Table 4 was created in line with the participants' opinions about the profession they could choose if they had the chance to make a second choice. In addition, the participants' views about the profession they would have preferred if allowed to make a second choice are shown in Table 4.

Table 4. Opinions of Teacher Candidates Regarding the Profession They Would Prefer If They Had the Chance to Make a Second Choice

\begin{tabular}{lc}
\hline Professions & Frekans \\
\hline Teaching & 17 \\
Lawyer & 2 \\
Performing Arts & 1 \\
Shipping & 1 \\
Computer Engineering & 1 \\
Architecture & 1 \\
\hline
\end{tabular}

Teacher candidates expressed their opinions of "re-teaching," "lawyer," "performing arts," "shipping," "computer engineering," and "architecture" about the profession they would prefer if they had the chance to make a second choice.

Teaching: In line with the opinions of prospective teachers about the profession they can choose if they have a chance to make a second choice, the most expression is "teaching." Most teacher candidates stated that they would choose the teaching profession again. Some of the opinions that may refer to this expression are given below.

"I do not think that I will give up my choice of teaching. I have wanted to be a teacher since I was little. I have already chosen my ideal profession... (P6)."

"Your communication with children has always been good. That's why dealing with children has always been fun for me. That's why I don't give up on my choice of teaching...(P10)."

"...I aim to improve myself constantly. I believe that the teaching profession is a suitable profession for this. That's why I probably wouldn't have changed my preference...(P14)."

In addition, the preferences of other nominees were "lawyer" (P18), "performing arts" (P19), "shipping" (P21), "computer engineering" (P22), and "architecture" (P23). It can be said that the participants' motivation towards the teaching profession is at a high level because the majority of the participants stated that they could choose the teaching profession as the second option. In addition, (P18), (P19), (P21), (P22), and (P23) indicate that they can choose different professions. When the views of the categories obtained in the study are examined, it can be said that some of these teacher 
candidates prefer the teaching profession with extrinsic motivation $[(\mathrm{P} 18),(\mathrm{P} 19),(\mathrm{P} 21),(\mathrm{P} 23)]$ and one teacher candidates have a salary expectation from teaching (P22). As a result, it can be concluded that teacher candidates who prefer the teaching profession with extrinsic motivation have lower motivation than the teaching profession.

\section{Discussion and Conclusion}

In this study, the reasons for choosing the teaching profession of teacher candidates, their expectations from the teaching profession, and their views on increasing the quality of the teaching program were examined. Qualitative research questions were formed in this direction, and answers were sought. Questions are addressed and discussed in turn below.

According to the first finding obtained from the research, the main theme was named as the teacher candidates' motivation for choosing a profession. The sub-themes are grouped under three headings as external reasons, altruistic reasons, and internal reasons. In the sub-theme of external reasons, there is a comfortable working environment, more holidays, regular income, a respectable profession, job guarantee, entry score, and recommendation categories. There are categories of serving humanity, being a role model, and touching people's lives in the altruistic reasons sub-theme. There are categories in the sub-theme of internal reasons, such as lifelong learning, teaching, communicating, an ideal job for me, teachers being role models, loving children, and love the school environment. Bergmark, Lundström, Manderstedt, and Palo (2018) stated in their study that internal, altruistic, and extrinsic motivations are effective in students' career choices. They have more than one motivation to choose the teaching profession. Çermik, Doğan, and Şahin (2010) state that primary school teacher candidates' reasons for choosing the teaching profession are affected by altruistic, internal, external, and self-seeker reasons. In addition, it is seen that sub-themes such as exam score, family pressure, ideal profession, communication skills, being a respected profession, being useful to society are obtained. It can be said that similar results were obtained with this study.

Similarly, in the study conducted by Low, Lim, Ch'ng, and Goh (2011), the reasons for choosing the teaching profession of teacher candidates were categorized as altruistic, internal, external, and other reasons. Similar sub-themes such as being a role model and loving children were obtained in the study. In a different research, Bursal and Buldur (2013) developed a scale on the reasons wh As a result of his factor analysis, it is stated that the scale is divided into two as intrinsic and extrinsic reasons. Still, the intrinsic reasons factor also consists of altruistic and intrinsic reasons teacher candidates choose the teaching profession. In addition, there are expressions similar to the categories obtained in this study in the scale items. These findings support the results of the study.

In line with the findings obtained from the research, the main theme of the future expectation from the profession was formed. It was concluded that the sub-themes were grouped under three headings as professional expectations, social expectations, and economic expectations. In the subtheme of professional expectations, there are categories of professional development, working environment, academic progress, raising equipped youth, and loving the profession. Social 
expectations sub-theme includes shaping the future, social status, and healthy communication categories. In the sub-theme of economic expectations, there are salary expectations and additional discounts categories. Gömleksiz, Kan, and Biçer (2010) applied a scale to determine prospective teachers' expectations from the teaching profession. The scale developed by the researchers was designed to measure the sociocultural, professional, financial, and career expectations of teacher candidates. In addition, when the scale items were examined, it was concluded that they were similar to the sub-themes obtained in this study. In his study, Koşar (2018) categorized prospective teachers' expectations into economic, social, task-related, individual, and negative expectations. In addition, there are sub-factors such as salary and livelihood expectation among financial expectations, social status and human relations among social expectations, classroom management, working environment, and professional development among job expectations. In the study conducted by Uras and Kunt (2006), teacher candidates' expectations from teaching were examined separately in four areas as social, economic, professional development, and legal expectations. In the study conducted by İncikab1, Biber, and Mercimek (2016), the expectations of teacher candidates were examined under the themes of professional development, academic development, and social development. In addition, it was stated that the most prominent theme was the professional development theme. Other research results support these results.

The expectations of teacher candidates and the attitudes and behaviors they develop towards realizing these expectations significantly affect the motivation and productivity of teacher candidates. It can be said that if the expectations of the teacher candidates from the profession are not realized, their motivation will decrease. In this case, the efficiency will also decrease (Uras \& Kunt, 2005). Teachers need to be supported in every way to create the future healthily. Teachers' professional expectations must be met (Şahin, 2011). However, it is said that there are differences between the expectations of teacher candidates before starting the profession and the situations they encounter after starting the profession (Yeşilyurt \& Karakuş, 2011). In particular, if the relevant institutions create education policies that will meet the professional, social, and economic expectations of individuals who have stepped into the teaching profession, it will ensure their satisfaction with the profession. This situation is considered necessary to increase the quality of the education system (Özsar1 2008).

When the opinions of the teacher candidates were evaluated, the category of increasing the quality of teacher education programs was obtained. In this category, the teaching method should be changed; entry conditions should be regulated, the number of students should be reduced, experienced instructors, effective communication, sufficient support, and physical facilities should be divided into sub-categories. When the results are examined, it is stated that teacher candidates' teaching methods should be changed. Therefore, Okçabol (2004) states in his study that the theoretical and practical courses of teacher candidates are not sufficient. In addition, it can be said that practice-based classes are more effective in gaining teaching skills (Şahin \& Kartal, 2013). 
Because the lessons learned theoretically become meaningful only if they are experienced with practice (Özkılıç, Bilgin \& Kartal, 2008). Teacher candidates expressed their opinions on regulating the conditions for entry to the teaching profession. In particular, it can be said that the central examination application reduces the quality of the teaching program. Supporting this statement, Can (2019) states in his study that among the obstacles to professional development is the application of central examination. Teacher candidates are under the pressure of achieving high success in central exams. Therefore, they tend to focus on the issues in the exam rather than increasing their teaching qualifications as teacher candidates (Barnes, 2005). In addition, this situation ensures that curricula are shaped according to central exams and puts the roles of teachers in the background (Can, 2017; Şahin, Uz Baş, Şahin Fırat, Sucuoğlu, 2012). In addition, it can be said that reducing the number of students, employing experienced instructors, effective communication, and creating sufficient support and physical opportunities can increase the quality of education. Studies carried out support these findings. In the study conducted by Öner and Y1lmaz (2019), statements such as giving importance to applied courses, reviewing the program conditions, reducing the number of students, and the competence of the instructors were obtained. These themes are similar to the themes obtained in this study. Hacettepe University, Faculty of Education (2017) states that planning the need for teachers in the medium and long term and determining the quotas accordingly will increase the quality of the teaching program. Similarly, Elma and Ergen (2016) state that to improve the quality of teacher education, the number of students should be reduced, and teachers should be selected according to their abilities.

As a result of the research, the opinions of the teacher candidates about the professions that they can choose if they have a chance to make a second choice were determined. A great majority of teacher candidates state that they will choose the teaching profession again. There are also teacher candidates who said they could choose lawyer, performing arts, shipping, computer engineering, and architecture. This situation reveals that some teacher candidates are not satisfied with their profession and intend to turn to other professions. In addition, it can be said that the majority of the teacher candidates who said they would be a teacher again chose the teaching profession for internal and altruistic reasons.

In contrast, teacher candidates who stated that they would prefer other professions preferred the teaching profession for external reasons. In the study conducted by Şahin, Zoraloğlu, and ŞahinFirat (2011), it was concluded that 15.7 of the students wanted to change the department they studied, $66.5 \%$ were satisfied with the department they studied, and $17.8 \%$ were undecided. Students who wanted to change the department they studied gave reasons such as thinking that the department they studied was unsuitable for their abilities and could find a job quickly when they graduated. When examined, these reasons mostly overlap with extrinsic motivation. It can be said that students who prefer their department with extrinsic motivation want to change departments. It can be concluded that individuals who choose the profession for intrinsic and altruistic reasons are satisfied 
with their profession. Therefore, Buldur and Bursal (2015) stated in their study that the reasons for choosing the profession of individuals whose ideal profession is teaching are internal and altruistic. In addition, it is said that the future expectations of teachers who choose their profession for internal and altruistic reasons are more favorable. It can be said that the attitudes of individuals who choose their profession for internal reasons are more profitable (Bozdoğan, Aydın, \& Yıldırım, 2007; Watt \& Richardson, 2008), while the future expectations of individuals who choose professions for external reasons are low (Beşoluk ve Horzum, 2011; Çermik, Doğan ve Şahin, 2010). In addition, it is stated that individuals who choose the teaching profession for internal reasons are satisfied and enjoy their jobs, do their jobs lovingly, and are successful (Özkubat \& Demiriz, 2013). When Herzberg's two-factor theory is examined, it is said that internal factors create high motivation for employees.

In contrast, extrinsic motivation does not create a suitable environment for motivating (Mahaney \& Lederer, 2006). In addition, individuals who act with altruistic motivation voluntarily help others and are concerned about others. Individuals with altruistic motivation have higher selfesteem, honor, and self-satisfaction (Eisenberg \& Mussen, 1989). When the results are examined, it can be said that the teacher candidates are united under three themes in the selection of the teaching program. It is observed that teacher candidates who prefer the teaching profession due to external reasons cannot identify themselves thoroughly with the profession and choose the profession in line with their expectations of interest or some situations that occur outside of themselves (Bastick, 2000; Boz \& Boz, 2008). It is said that this situation brought the teaching profession to the point of quitting over time (Erden, 2008). In addition, it can be said that teachers who choose the teaching profession for intrinsic and altruistic reasons have higher teaching motivation and work efficiently (Sinclair, 2008). In this case, it can be deduced that the attitudes of the teacher candidates who have an altruistic and intrinsic motivation to the teaching profession are more favorable than those who have extrinsic motivation.

\section{Suggestions}

The feelings, thoughts, and expectations of teachers, who are one of the most critical stakeholders of the school, about the teaching profession since their candidacy are an issue that should be considered. In addition, the experiences of teacher candidates should be determined to increase the quality of the education program. Therefore, it is thought that the opinions of teacher candidates on this subject are essential.

Teacher candidates stated that external, altruistic, and internal reasons influenced choosing the teaching profession. Although internal and altruistic reasons are more dominant, external reasons are also effective. When external reasons are examined, teacher candidates choose to teach because they think it is a comfortable working environment. It can be said that teacher candidate who chooses their profession due to intrinsic and altruistic reasons will be more successful (Buldur \& Bursal 2015; Özkubat \& Demiriz, 2013). For this reason, it is recommended that individuals be guided to 
choose their profession by their interests and abilities during high school, and they should be guided for career choices in this direction. In particular, practices should be developed to prevent the teaching profession from choosing for external reasons. They should be encouraged to choose the teaching profession for altruistic and internal reasons.

Teacher candidates stated that they have some expectations from the teaching profession. These are professional, social, and economic expectations. It is necessary to provide the essential training to ensure teachers' professional development, meet their academic expectations, and become well-equipped individuals in their profession. In this context, it is suggested that the subjects they lack in terms of teaching professional competencies (professional development, student recognition, learning-teaching process, monitoring and evaluation of learning development, school family and community relations, program and content information) should be determined. The necessary weights should be given in the curriculum to ensure the professional expectations of teachers. In addition, social and economic expectations include expectations such as status, respect, salary expectation. It is recommended to make legal, statutory, or regulatory arrangements to improve the status of the teaching profession. A success-oriented salary system can be introduced to meet the economic expectations of teachers. Or, legally, the working conditions of teachers can be reviewed to increase their social status. Arrangements made on these issues are essential in terms of revealing the point of view of the political authority towards teachers, thus increasing the social status.

Teacher candidates made suggestions such as changing the teaching method and rearranging the entry conditions of the teaching program to increase the quality of the teacher education program. Considering the importance of the teaching profession for society, it is recommended that policymakers take these and other suggestions into account and take the necessary precautions. In this context, essential skills should be determined in line with the needs of both the teacher and society. It is recommended to carry out studies to gain them to teachers.

Although most teacher candidates stated that they would choose the teaching profession again if they had the chance to make a second choice, the number of those who said they could choose different professions is relatively high. In this case, it is necessary to investigate and reveal the thoughts of these teacher candidates about why they might choose another department. In addition, guiding prospective teachers about the department that suits their interests and abilities can help them choose the right profession. In summary, it is recommended to establish a system that can determine the selection of suitable candidates for the teaching profession. In this direction, a great deal of work falls on policymakers.

In the future, research may be searched to expose why some teacher candidates want to choose a different department if they choose again. Qualitative research on this subject can provide the emergence of the existing situation as a whole. Whether teachers' professional self-efficacy or job performance differ in terms of their motivation to choose the teaching profession (internal, extrinsic, and altruistic) can be examined with quantitative research. 
Ethical Approval: This research was carried out with the permission of Cumhuriyet University Scientific Research and Publication Ethics Social and Human Sciences board with the decision numbered E-60263016-050.06.04-57251 dated 12/07/2021.

Conflict Interest: The author has no conflict of interest to declare.

Authors Contributions: The corresponding author contributed to the preparation and editing of the article.

\section{Kaynakça}

Alkan, C. (2000). Meslek ve öğretmenlik mesleği. V.Sönmez (Ed.), Öğretmenlik mesleğine giriş (s.191-230) içinde. Ankara: Anı Yayınları.

Azman, N. (2013). Choosing teaching as a career: Perspectives of male and female Malaysian student teachers in training. European Journal of Teacher Education, 36(1), 113-130. doi: $\underline{10.1080 / 02619768.2012 .678483}$

Aycan, M. M. (2020). Öğretmenlerde mesleki motivasyon ve örgütsel vatandaşllk davranışı arasındaki ilişki (Yayımlanmamış yüksek lisans tezi). Pamukkale Üniversitesi, Eğitim Bilimleri Enstitüsü, Denizli.

Bergmark, U., Lundström, S., Manderstedt, L., \& Palo, A. (2018). Why become a teacher? Student teachers' perceptions of the teaching profession and motives for career choice. European Journal of Teacher Education, 41(3), 266-281. doi: 10.1080/02619768.2018.1448784

Balyer, A. \& K. Özcan. (2014). Choosing teaching profession as a career: Students' reasons. International Education Studies 7(5), 104-115. doi:10.5539/ies.v7n5p104.

Barnes, M. (2005). The Discriminatory effects of High-Stakes Testing in Georgia: Exploring causes and solutions. Education Law and Policy Forum, Education Law Consortium, The University ofGeorgia, Athens, GA.

Bastick, T. (2000). Why teacher trainees choose the teaching profession? Comparing trainees in metropolitan and developing countries. International Review of Education, 46(3/4), 343-349.

Beşoluk, Ş. \& Horzum, M. B. (2011). Öğretmen adaylarının meslek bilgisi, alan bilgisi dersleri ve öğretmen olma isteğine ilişkin görüşleri. Ankara Üniversitesi Eğitim Bilimleri Fakültesi Dergisi, 44(1), 17-49.

Boz, Y. \& Boz. N. (2008). Kimya ve matematik öğretmen adaylarının öğretmen olma nedenleri. Kastamonu Ë̆itim Dergisi, 16(1), 137-144.

Bozdoğan, A., Aydın, D. \& Yıldırım, K. (2007). Öğretmen adaylarının öğretmenlik mesleğine ilişkin tutumları. Ahi Evran Üniversitesi Kırşehir Eğitim Fakültesi Dergisi, 8(2), 83-97

Buldur, S. \& Bursal, M. (2015). The impact levels of career choice reasons of preservice science teachers and their future career expectations. Necatibey Ĕgitim Fakültesi Elektronik Fen ve 
Matematik Ĕgitimi Dergisi [Necatibey Faculty of Education Electronic Journal of Science \& Mathematics Education], 9(1), 81-107.

Bursal, M. \& Buldur, S. (2013). Fen bilgisi öğretmen adayları için öğretmenlik tercih nedenlerini derecelendirme ve geleceğe yönelik beklentiler ölçekleri geliştirme çalışması. Turkish Journal of Teacher Education, 2(1), 47-64.

Camelia, S., \& Elisabeta, P. M. (2013). Initial teacher training in Romania-a critical view. ProcediaSocial and Behavioral Sciences, 76, 780-784. doi: 10.1016/j.sbspro.2013.04.205

Can, E. (2019). Öğretmenlerin meslekî gelişimleri: Engeller ve öneriler. Eğitimde Nitel Araştırmalar Dergisi - Journal Of Qualitative Research In Education, 7(4), 1618-1650. doi: 10.14689/Issn.2148-2624.1.7c.4s.14m

Can, E. (2017). Öğrenci görüşlerine göre merkezî sınavların etkilerinin belirlenmesi. Akademik Sosyal Araştırmalar Dergisi, 5(58), 108-122

Can, Y. \& Soyer, F. (2008). Beden eğitimi öğretmenlerinin sosyo-ekonomik beklentileri ile iş tatmini arasındaki ilişki. Gazi University Journal of Gazi Educational Faculty (GUJGEF), 28(1), 61-74

Creswell, J. W. (2013). Qualitative, quantitative and mixed method approaches research design. (Çev. Ed. Demir, SB). Ankara: Eğiten Kitap

Çermik, H., Dogan, B. \& Sahin, A. (2010). Sınıf öğretmenliği öğretmen adaylarının öğretmenlik mesleğini tercih sebepleri. Pamukkale Üniversitesi Eğitim Fakültesi Dergisi, 28(2), 201-212.

Eisenberg, N. \& Mussen, P. H. (1989). The roots of prosocial behavior in children. Cambridge University Press.

Elma, C. \& Ergen, Y. (2016). Yeni mezun sınıf öğretmenlerinin sınıf öğretmeni yetiştirme programına ilişkin görüşleri. Kesit Akademi Dergisi, 2(4), 185-211.

Erden, M. (2008). Eğitim bilimlerine giriş. Ankara: Arkadaş Yayınevi.

Ergün, M. \& Avc1, S. (2012). Hollanda ve Türkiye'deki fen bilgisi öğretmeni yetiştirme programları hakkında öğretmen adaylarının görüşlerinin karşılaştırılması. Necatibey Eğitim Fakültesi Elektronik Fen ve Matematik Eğitimi Dergisi (EFMED), 6(1), 151-170.

Gömleksiz, M. N., Kan, A. Ü. \& Biçer, S. (2010). Öğretmen adaylarının öğretmenlik mesleğinden beklentileri (Frrat Üniversitesi örneği). Education Sciences, 5(2), 479-500.

Hacettepe Üniversitesi, Eğitim Fakültesi. (2017). Türkiye'de Öğretmen Ĕ̆itimi ve İstihdamı: Mevcut Durum öneriler. Erişim Adresi: http://fs.hacettepe.edu.tr/egitim/Raporlar/OgretmenEgitimi-istihdam_Raporu.pdf], Erişim tarihi: 2 Kasım 2021.

Haciömeroğlu, G. \& Taşkın, Ç. (2010). Fen bilgisi öğretmenliği ve ortaöğretim fen ve matematik alanları ofma eğitimi bölümü öğretmen adaylarının öğretmenlik mesleğine ilişkin tutumları. Ahi Evran Üniversitesi Kırşehir Eğitim Fakültesi Dergisi, 11(1), 77-90. 
Hattie, J. (2009). Visible learning a synthesis of over 800 meta-analyses relating to achievement. London: Routledge.

İncikabı, L., Biber, A. Ç. \& Mercimek, O. (2016). İlköğretim matematik öğretmen adaylarının programı tercih nedenleri ve beklentileri üzerine bir araştırma. Adlyaman Üniversitesi Sosyal Bilimler Enstitüsü Dergisi, 8(22), 165-188. doi: /10.14520/adyusbd.67923

Jamil, H. (2014). Teacher is matter for education quality: A transformation of policy for enhancing the teaching profession in Malaysia. Journal of International Cooperation in Education, 16(2), 181-196.

Karadağ, R. (2012). Türkçe öğretmeni adaylarının öğretmenlik mesleğine ilişkin tutumları ve öğretmenlik mesleğini tercih nedenleri. Humanities Sciences, 7(2), 44-66.

Koşar, D. (2018). Öğretmen adaylarının meslekten beklentilerine ilişkin görüşlerinin incelenmesi: Nitel bir araştırma. Journal of International Social Research, 11(56), 575, 585.

Kuzgun, Y. (2008). Meslek seçiminde bilinmesi gerekenler. Ankara: Ösym Yayınları

Low, E. L., Lim, S. K., Ch'ng, A., \& Goh, K. C. (2011). Pre-service teachers' reasons for choosing teaching as a career in Singapore. Asia Pacific Journal of Education, 31(2), 195-210. doi: $\underline{10.1080 / 02188791.2011 .567441}$

Merriam, S. B., \& Grenier, R. S. (2019). Introduction to qualitative research. qualitative research in practice: Examples for Discussion and Analysis. San Francisco: Jossey-Bass

Moran, A., Kilpatrick, R., Abbot, L., Dallat, J., \& McClune, B. (2001). Training to teach: Motivating factors and implications for recruitment. Evaluation and Research in Education, 15(1), 1732. doi: $\underline{10.1080 / 09500790108666980}$

Okçabol, R. (2004, Temmuz). Öğrenci, ögrretmen, öğretmen adayı ve ögretim eleman gözüyle ögretmen yetiştirme., XIII. Ulusal Eğitim Bilimleri Kurultayı, İnönü Üniversitesi, Eğitim Fakültesi, Malatya.

Öner, M. \& Yılmaz, R. K. (2019). Sınıf öğretmenliği eğitiminin niteliğinin artırılmasına yönelik öğretmen adayları ve öğretim elemanı görüşleri. Trakya Eğitim Dergisi, 9(4), 847-868. doi: $\underline{10.24315 / \text { tred.533604 }}$

Özkılıç, R., Bilgin, A., \& Kartal, H. (2008). Öğretmenlik uygulaması dersinin öğretmen adaylarının görüşlerine göre değerlendirilmesi. Illköğretim Online, 7(3), 726-737.

Özkubat, S. \& Demiriz, S. (2013). Çevreye karşı motivasyon ölçeğinin okul öncesi öğretmen adayları üzerinde geçerlik güvenirlik çalışması. Amasya Üniversitesi Eğitim Fakültesi Dergisi, 2(1), 87-114.

Özsarı, İ. (2008). Ĕgitim fakültesi son sınıf öğrencilerinin KPSS merkezi sınavı odaklı gelecek kaygıları ve mesleki beklentileri (Yayımlanmamış yüksek lisans tezi). İstanbul Üniversitesi, Sosyal Bilimler Enstitüsü, İstanbul. 
Papanastasiou, C., \& Papanastasiou, E. (1997). Factors that influence students to become teachers. Educational Research and Evaluation, 3(4), 305-316. doi: $\underline{10.1080 / 1380361970030402}$

Patton, M. Q. (2005). Qualitative research. New York: John Wiley \& Sons, Ltd

Sinclair, C. (2008). Initial and changing student teacher motivation and commitment to teaching. Asia-Pacific Journal of Teacher Education, 36(2), 79-104. doi:10.1080/13598660801971658.

Şahin, İ. (2011). Öğretmen adaylarının öğretmen istihdamı ve mesleki geleceklerine ilişkin görüşleri. Kuram ve Uygulamada Eğitim Bilimleri, 11(3), 1167 - 1184.

Şahin, Ç. \& Kartal, O. Y. (2013). Sınıf öğretmeni adaylarının sınıf öğretmeni yetiştirme programı hakkındaki görüşleri. Uşak Üniversitesi Sosyal Bilimler Dergisi, 6(1), 164-179.

Şahin, İ., Zoraloğlu, Y. R. \& Şahin-Fırat, N. Ş. (2011). Üniversite öğrencilerinin yaşam amaçları, eğitsel hedefleri üniversite öğreniminden beklentileri ve memnuniyet durumları. Kuram ve Uygulamada Eğitim Yönetimi, 3(3), 429-452.

Şahin, S., Uz Baş, A., Şahin Fırat, N. \& Sucuoğlu, H. (2012). İlköğretim okulu öğrenci ile öğretmenlerinin ortaöğretime geçiş sistemine ilişkin görüşleri. International Journal of Human Sciences, 9(2), 847-878.

Şara, P. \& Kocabaş, A. (2012). Sınıf öğretmeni adaylarının sınıf öğretmenliğini tercih nedenleri ve aldıkları eğitimle ilgili görüşleri. Turkish International Journal of Special Education and Guidance \& Counselling (TIJSEG), 1(2), 8-17.

Tataroğlu, B., Özgen, K. \& Alkan, H. (2011). Matematik öğretmen adaylarının öğretmenliği tercih nedenleri ve beklentileri. 2nd International Conference on New Trends in Education and Their Implications. Ankara: Siyasal Kitabevi.

Thomson, M. M., Turner, E. J., \& Nietfeld, J. L. (2012). A typological approach to investigate the teaching career decision: Motivations and beliefs about teaching of prospective teacher candidates. Teaching and Teacher Education 28(3), 324-335. doi:10.1016/j.tate.2011.10.007.

Tunca, N., Alkın-Şahin, S., Oğuz, A. \& Bahar-Güner, H. O. (2015). Qualities of ideal teacher educators. Turkish Online Journal of Qualitative Inquiry, 6(2),123-148. doi: $\underline{10.17569 / \text { tojqi.48192 }}$

Uras, M. \& Kunt, M. (2006). Öğretmen adaylarının öğretmenlik mesleğinden beklentileri ve beklentilerinin karşılanmasını umma düzeyleri. Pamukkale Üniversitesi Eğitim Fakültesi Dergisi, 19(1), 71-83.

Üstüner, M. (2006). Öğretmenlik mesleğine yönelik tutum ölçeğinin geçerlik ve güvenirlik çalışması. Kuram ve Uygulamada Eğitim Yönetimi, 12(45), 109-127. 
Watt, H. M., \& Richardson, P. W. (2008). Motivations, perceptions, and aspirations concerning teaching as a career for different types of beginning teachers. Learning and Instruction, 18(5), 408-428.

Yeşilyurt, E. \& Karakuş, M. (2011). The problems teachers encountered during the candidacy process. International Online Journal of Educational Sciences, 3(1), 261-293.

Yıldırım, A. (1999). Nitel araştırma yöntemlerinin temel özellikleri ve eğitim araştırmalarındaki yeri ve önemi. Eğitim ve Bilim, 23(112), 7-17.

Yıldırım, A. \& Şimşek, H. (2013). Sosyal bilimlerde nitel araştırma yöntemleri. Ankara: Seçkin Yayınc1lk.

Yıldırım, N. \& Öner, S. (2016). Etkili/başarılı sınıf öğretmenleri üzerine nitel bir analiz. Ahi Evran Üniversitesi Kırşehir Eğitim Fakültesi Dergisi, 17(3), 135-155. 